\title{
The Physical Basis for Predicting Atlantic Sector Seasonal-to-Interannual Climate Variability*
}

\author{
YOCHANAN KUSHNIR \\ Lamont-Doherty Earth Observatory, Palisades, New York \\ WALter A. Robinson \\ University of Illinois at Urbana-Champaign, Urbana, Illinois \\ Ping Chang \\ Texas A\&M University, College Station, Texas \\ ANDREW W. ROBERTSON \\ International Research Institute for Climate Prediction, Palisades, New York
}

(Manuscript received 15 November 2004, in final form 6 July 2005)

\begin{abstract}
This paper reviews the observational and theoretical basis for the prediction of seasonal-to-interannual (S/I) climate variability in the Atlantic sector. The emphasis is on the large-scale picture rather than on regional details. The paper is divided into two main parts: a discussion of the predictability of the North Atlantic Oscillation (NAO) - the dominant pattern of variability in the North Atlantic - and a review of the tropical Atlantic prediction problem. The remote effects of El Niño are also mentioned as an important factor in Atlantic climate variability. Only a brief discussion is provided on the subject of South Atlantic climate predictability.

Because of its chaotic dynamical nature, the NAO and its related rainfall and temperature variability, while highly significant over Europe and North America, are largely unpredictable. This also affects the predictive skill over the tropical Atlantic, because the NAO interferes with the remote influence of El Niño. That said, there appears to be an insufficiently understood, marginal signal in the NAO behavior that may be predictable and thus useful to certain end users. It is manifested in the deviation of the NAO temporal behavior from first-order autoregressive behavior.

Tropical Atlantic climate variability centers on the sensitivity of the marine ITCZ to remote forcing from the equatorial Pacific and interactions with underlying sea surface temperature (SST) variability. Both mechanisms are potentially predictable - that is, given the underlying SSTs and the strength of El Niño, one could determine with a high degree of skill the anomalies in ITCZ position and intensity. However, local SSTs are easily affected by largely unpredictable North and South Atlantic phenomena, such as the NAO. In addition, the local ocean-atmosphere coupling in the Atlantic acts on relatively short time scales. Thus, in reality the level of skill indicated by forced model simulations are difficult to achieve. The use of coupled models may improve the prospects of tropical Atlantic prediction.
\end{abstract}

\section{Introduction}

Prediction of seasonal-to-interannual (S/I) variability hinges on determinism in the evolution of the atmo-

\footnotetext{
* Lamont-Doherty Earth Observatory Contribution Number 6936.
}

Corresponding author address: Yochanan Kushnir, LamontDoherty Earth Observatory, 61 Route 9W, Palisades, NY 10964. E-mail: Kushnir@ldeo.columbia.edu spheric low-frequency circulation, in time and space. Such determinism can come from the influence of external forces that are not affected by climate itself-for example, volcanic activity-or from the internal dynamics of the climate system. Notably, deterministic, internal, atmospheric dynamical processes are, for the most part, chaotic (Lorenz 1963), effectively contributing a stochastic component to short-term statistics derived from the time averaging of weather. The resulting "natural climate variability" or "climate noise" is inherently unpredictable (Leith 1973; Madden 1976), imply- 
ing that prospects for short-term climate prediction lie in the interaction of the atmosphere with the slower components of the climate system - the ocean and land surfaces-which can yield "modes" of variability that have either a quasi-periodic evolution or a large persistence. This is why $\mathrm{S} / \mathrm{I}$ prediction is centered on the sensitivity of the atmospheric circulation to persistent surface anomalies.

Because the study of climate variability is largely empirical, the normal evolution of the science of climate prediction has been based on a search for observed evidence for large persistence or quasi periodicity in the atmosphere (and ocean), followed by an attempt to understand the theoretical basis for the latter and, in recent years, efforts to replicate it in climate models. Establishing a theoretical and modeling foundation for observational evidence is particularly important because it enables interpretation and correct application of results based on the relatively short observational records and because it resolves some of the uncertainty resulting from the small "signal-to-noise" ratios often inherent in climate variability.

In the following appraisal of the physical basis for climate prediction in the Atlantic basin, we address the ability to predict the year-to-year variation in monthly or seasonal averages some time in advance, on the basis of internal interactions. The paper does not discuss phenomena and mechanisms associated with longerterm predictability, such as those that might be associated with decadal variability or climate trend or those that might be associated with anthropogenic forcing. While these do affect interannual variability, a discussion of the dynamical basis for their prediction is beyond the scope of this paper. Only a short discussion is presented regarding the effects of volcanic forcing, which can have a marked effect on S/I variability.

The paper is divided as follows: In section 2 we briefly describe the salient elements of climate variability in the Atlantic basin: El Niño-Southern Oscillation (ENSO), the North Atlantic Oscillation (NAO), and the sea surface temperature (SST) patterns associated with tropical Atlantic variability (TAV). We demonstrate their impact on two primary surface climate variables: temperature and rainfall. In section 3 we discuss the dynamical nature of the NAO and its interaction with the ocean and land and their ramifications for predictability. Also discussed in this context is the interaction with the stratosphere, which has recently received considerable attention as a source of predictable, lowfrequency signals in winter. In section 4 we discuss the theory behind TAV and its predictability, particularly in conjunction with the large influence exerted on this region by El Niño. Section 6 offers a summary and closing remarks regarding the prospects of future developments in S/I prediction in the Atlantic basin.

\section{The patterns of climate variability in the Atlantic sector}

The notion that $\mathrm{S} / \mathrm{I}$ variability is associated with large-scale patterns linking fluctuations in remote areas of the world is captured in the early-twentieth-century work of Sir Gilbert Walker and collaborators (Walker 1924; Walker and Bliss 1932). They systematically documented several so-called teleconnection patterns and used them to characterize and project a range of climate impacts. The appealing aspects of such patterns are their coherent structures and repeated occurrence; therefore monitoring them should at least aid in nowcasting climate. Walker's work and subsequent research culminated in the well-known study of teleconnections by Wallace and Gutzler (1981), which added a modern, objective approach to the more descriptive work of the early investigators. From this and more recent studies, it is now recognized that there are three major phenomena associated with climate variability in and around the Atlantic basin:

(i) The NAO, which affects the climate of the North Atlantic from subtropical to polar latitudes (Hurrell et al. 2002). In recent years Thompson and Wallace $(2000,2001)$ broadened the conceptual understanding of this seesaw phenomenon by introducing a hemispheric counterpart they named the Northern Hemisphere annular mode (NAM). The two patterns are taken here as "two-paradigms of the same phenomenon" (Wallace 2000). The NAO has a strong influence on North Atlantic SST that has long been suspected of affecting its temporal behavior (Bjerknes 1964; Wallace et al. 1992; Deser and Blackmon 1993; Kushnir 1994; Visbeck et al. 2002).

(ii) ENSO, which influences the global atmospheric circulation, particularly in the Tropics. ENSO's influence on the tropical Atlantic is exerted directly through the tropical "waveguide" (Klein et al. 1999; Chiang et al. 2002), the Pacific North American (PNA) wavetrain (Trenberth et al. 1998), and indirectly through its influence on tropical Atlantic SST (Hastenrath et al. 1987; Enfield and Mayer 1997).

(iii) TAV, which affects the seasonal migration of the intertropical convergence zone (ITCZ) and hence the rainfall over South America and West Africa (Xie and Carton 2004). It is typically discussed in terms of two different patterns: an eastern equatorial SST anomaly associated with changes in the 


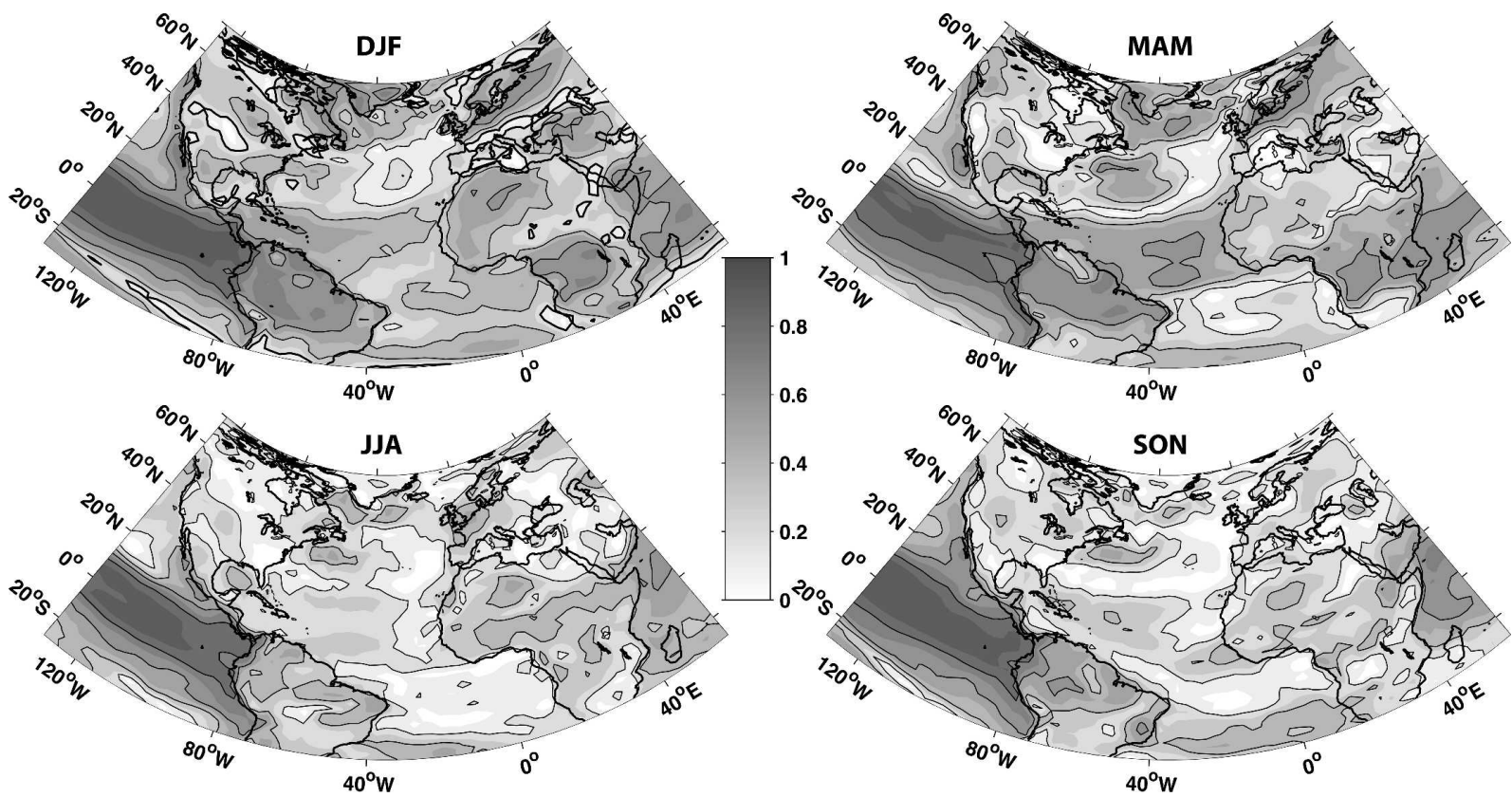

FIG. 1. Correlation between observed and reconstructed seasonal surface temperatures. Reconstruction is based on a multiple regression on the winter NAO index and the same-season Niño-3 index. (top left) December-February; (top right) March-May; (bottom left) June-August; (bottom right) September-November. Temperature data are from NCEP-NCAR reanalysis, 1950-2003. Contour interval is 0.2 and shading is according to the grayscale in the middle.

intensity of the so-called Atlantic cold tongue and off-equatorial variability associated with changes in the strength of the cross-equatorial temperature gradient. Each of these patterns acts during a different time of the year (Sutton et al. 2000).

It should be emphasized however, that in the midlatitudes in particular, the spatial and temporal spectrum of climate variability could not be captured by a single teleconnection pattern. While the NAO dominates variability in the North Atlantic on time scales longer than 10 days or so, it is not the only pattern emerging in an objective analysis of the covariance field. Variability in the form of the eastern Atlantic (EA) and Eurasian (EU) patterns also deserves attention for its more localized, though weaker overall, influence (Wallace and Gutzler 1981; Barnston and Livezey 1987). In part, this diversity has been interpreted as indicating the existence of a continuum of dipolar, low-frequency patterns in the northern ocean basins, with the NAO dominant in the monthly and seasonal mean fields during winter (Kushnir and Wallace 1989), but variations genuinely independent of the NAO may also exist. Local climates may also be affected by local conditions not clearly associated with the large-scale teleconnection patterns. These are not discussed in the present review.

To quantify the influence of these atmospheric and
SST patterns, we use their historical amplitudes and phases as indices for reconstructing historical surface air temperature and precipitation, by means of a multiple, linear regression analysis. The correlation between the reconstructed variables and observations provides an upper limit for the ability to specify the climate from these patterns. Here we focus on the two dominant patterns-ENSO and the NAO. This approach entails an implicit assumption that the evolution of TAV depends, to a large extent, on these remote forcing factors (Czaja et al. 2002).

The ability to specify climate anomalies using the Niño- $3^{1}$ and the $\mathrm{NAO}^{2}$ indices is depicted in Fig. 1. Here the monthly averaged, 2-m aboveground air temperature from the National Centers for Environmental Prediction-National Center for Atmospheric Research (NCEP-NCAR) reanalysis is used as a proxy for the actual surface temperature field. The temperature data are seasonally averaged, regressed on the observed indices between 1950 and 2003 (using multiple regression) and then reconstructed. Figure 2 shows a similar

\footnotetext{
${ }^{1}$ An indicator of ENSO calculated by averaging the SST anomaly in the region $90^{\circ}-150^{\circ} \mathrm{W}$ and $5^{\circ} \mathrm{S}-5^{\circ} \mathrm{N}$, based here on the Kaplan et al. (1998) SST reconstruction.

${ }^{2}$ Here the station index of Hurrell (1995) is used (http:// www.cgd.ucar.edu/cas/jhurrell/indices.html).
} 


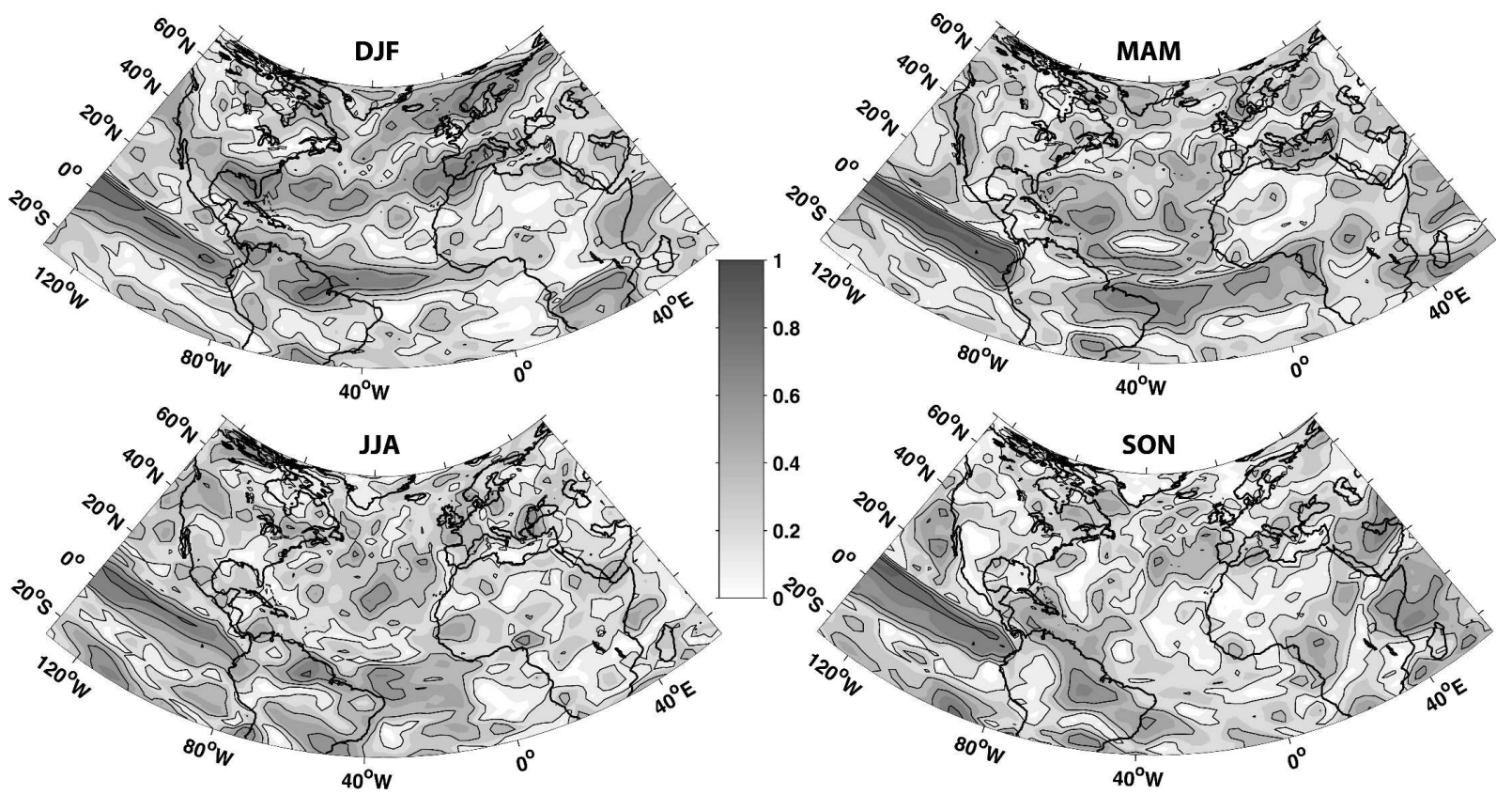

FIG. 2. Correlation between observed and reconstructed seasonal precipitation. Reconstruction is based on a multiple regression on the winter NAO index and the same-season Niño-3 index. (top left) December-February; (top right) March-May; (bottom left) June-August; (bottom right) September-November. Precipitation data are from NASA GPCP satellite and rain gauge blend reconstruction, 1980-2003. Contour interval is 0.2 and shading is according to the grayscale in the middle.

analysis but for rainfall. ${ }^{3}$ The analysis is performed for all four seasons. Here we keep the NAO index at its same-year boreal winter (December-March) value and the Niño-3 index at its same-season value. By using the wintertime NAO index we account for the relatively large coherence displayed by this pattern during the boreal winter and its persistent imprint on surface fields, mainly the SST (Visbeck et al. 2002). In using the simultaneous Niño-3 we recognize its large persistence and the present-day skill in predicting this index.

The most significant and large-scale impacts emerge in boreal winter (December-February) and spring (March-May). In these seasons there are large areas where $16 \%-36 \%$ (and above) of the surface temperature and rainfall variance (correlation of 0.4 to 0.6 ) can be reconstructed. An examination of the individual influences of ENSO and the NAO (not shown) indicates that both phenomena are equally important over the Atlantic sector, but their regions of influence differ: El Niño dominates the Tropics and subtropics and the NAO rules over the middle and high latitudes. The influence is discernible on both sides of the Atlantic. El Niño is very important for tropical prediction. The

\footnotetext{
${ }^{3}$ Rainfall data are from the National Aeronautics and Space Administration (NASA) Global Precipitation Climatology Project (GPCP), 1980-2003.
}

NAO is also associated with boreal wintertime temperature anomalies over North Africa and the Middle East. El Niño is associated with significant rainfall anomalies over North America and the Atlantic and with weaker anomalies over Europe, mainly along the Mediterranean. Thus, understanding and improving the prediction of ENSO and NAO is central to improving the prediction of climate anomalies in the Atlantic ba$\sin$.

\section{Predictability of the NAO}

\section{a. The physical nature of the NAO}

The NAO is an equivalent barotropic seesaw in atmospheric pressure or geopotential height between middle latitudes and the sub-Arctic. Its spatial scale is determined by the fact that it is a quasi-stationary structure-thus its Rossby wave frequency must be approximately zero. In its positive phase it represents a poleward shift of the North Atlantic jet and its associated storm track (Fig. 3). While the NAO is typically considered a middle-to-high latitude pattern, it has a significant association with variability in the zonal winds well into the Tropics. In comparison, El Niño's influences in the Atlantic basin (Fig. 3, bottom panel) displays a weaker pattern of upper-level westerly anomalies in the Tropics and bands of easterly and westerly 

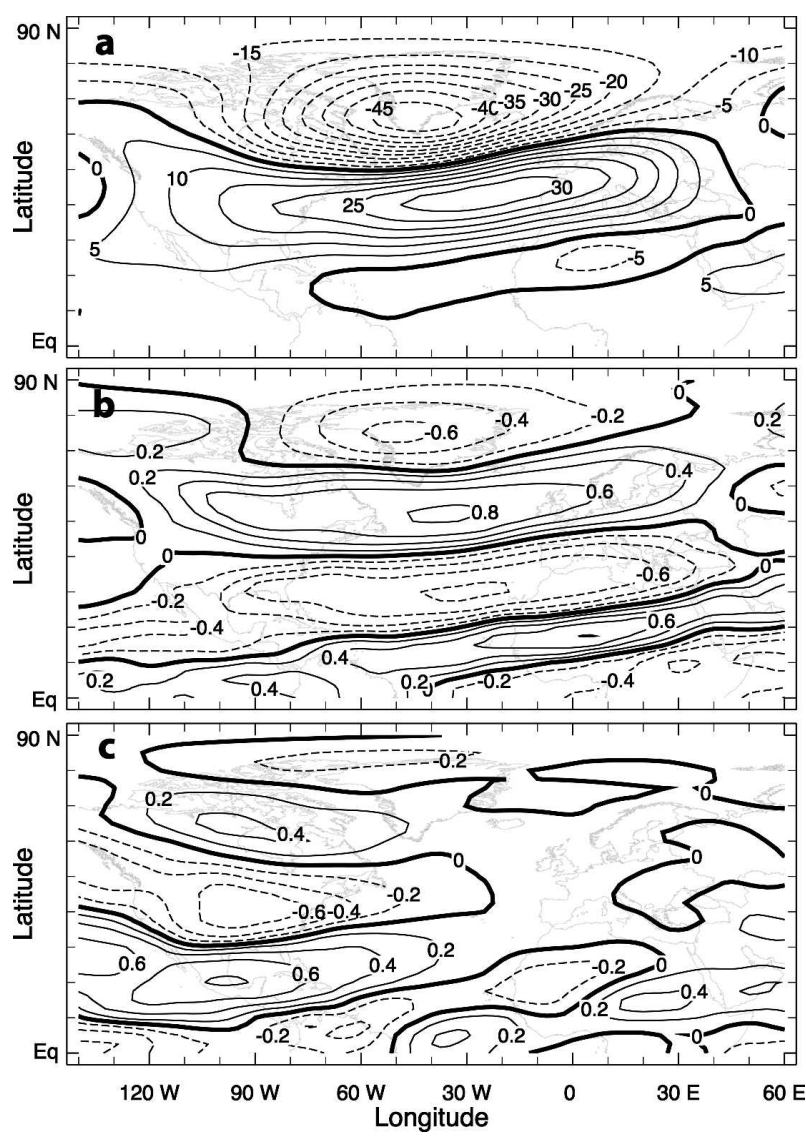

FIG. 3. The NAO: (a) DJF 500-hPa geopotential heights regressed on the National Oceanic and Atmospheric Administration (NOAA) Climate Prediction Center (CPC) NAO index (contour interval $=10 \mathrm{~m}$ ) and (b) DJF 300-hPa zonal winds correlated with the NAO index (contour interval $=0.1$ ). (c) The $300-\mathrm{hPa}$ winds correlated with the Niño-3 index. All figures were calculated using online tools at the Climate Diagnostics Center Web site (http://www.cdc.noaa.gov/Correlation/).

midlatitude anomalies, nearly in meridional quadrature with the NAO pattern. Thus, the direct influence of El Niño on the NAO is slight. The El Niño pattern over the Atlantic is approximately a superposition of a forced stationary Rossby wave train (Hoskins and Karoly 1981; Wallace and Gutzler 1981) and a more recently recognized zonally symmetric response to tropical warming (Seager et al. 2003).

Time series of the NAO are nearly indistinguishable from red noise, with a decorrelation time of less than 10 days during winter-the season of its greatest persistence (Feldstein 2000a). Longer time scale behavior in the NAO should, at the least, be considered as the result of sampling time averages of a red-noise process-a prospect which offers little hope for extended range prediction. An alternative proposition is that it is associated with behavior of the NAO that does not conform to the red-noise model. Here we focus on the possible mechanisms that explain such deviations from rednoise behavior. We also review the evidence that such deviations do, indeed, exist.

The NAO day-to-day persistence is most likely provided by reinforcing interactions with transient baroclinic eddies in the storm track. In fact, an alternative description of the NAO is that it is a self-maintaining poleward or equatorward shift in the location of the eddy-driven, extratropical jet and its associated storm track across the North Atlantic (Lee and Kim 2003). The closely related NAM is just such a meridional shift of circumpolar extent. The eddies reinforce the NAO only in the average sense, however, and most transienteddy forcing of the NAO cannot be parameterized as a feedback. The NAO can arise internally from local variations in the climatological stationary waves (DeWeaver and Nigam 2000) or from remotely forced large-scale disturbances that "break" over the North Atlantic (Franzke et al. 2004).

Given its many possible sources, none of which arises from processes that are predictable over longer times than those of conventional medium-range weather forecasting, and given its typical decay time on the order of 10 days, it would appear that the prospects for seasonal and longer forecasting of the NAO are slight. What potential does exist derives from interactions of the troposphere with its more slowly evolving boundaries: the sea surface, soil moisture, snow cover, and the stratosphere. These boundary forces are all thought to be weak in their influence in comparison with the robust intrinsic variability of the NAO. Thus, it should not be expected that any boundary influence would fix the NAO in one sign or another during an entire season. Rather, the best that can be hoped for is a small but persistent bias in the sign of the NAO. Even after averaging over a month or a season, most of the variability in the NAO is likely attributable to the stochastic variations that remain after performing a time average of a red-noise process (Feldstein 2000a,b).

\section{b. Intraseasonal persistence of the NAO}

Before turning to mechanisms that can drive persistent monthly anomalies, it is worth considering the evidence that such mechanisms are in operation. Figure 4 shows the seasonal cycle of 1-month lag autocorrelation of the monthly mean NAO index from 1950 to 2004 (calculated using principal component analysis; see http://www.cpc.ncep.noaa.gov/data/teledoc/nao.shtml). Month Carlo simulations of the correlation show that highly significant values of persistence occur in winter, between November and March. During the rest of the year persistence values calculated from observations are not significant. It is readily shown that the large 


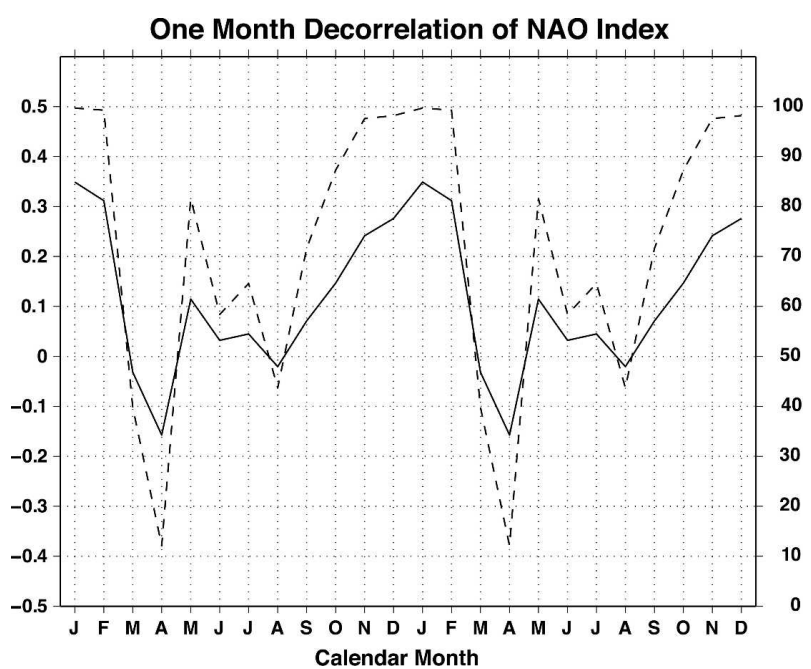

FIG. 4. Month-to-month (January-to-February, February-toMarch, March-to-April, etc.) autocorrelations of the NAO index, 1950-2003 (index data from CPC; see Fig. 3). The annual cycle is repeated twice for clarity. The dashed line is drawn at the $95 \%$ confidence interval.

monthly decorrelation values during winter are higher than expected from successive 30-day averages of a daily red-noise process. The latter are given by the following expression:

$$
\operatorname{Cor}[\bar{x}(t), \bar{x}(t+T)]=\left(\frac{\tau}{T}\right) \frac{e^{-T / \tau}[\cosh (T / \tau)-1]}{\left[1-\frac{\tau}{T}\left(1-e^{-T / \tau}\right)\right]} .
$$

Where $T$ is the averaging interval and $\tau$ is the $e$-folding time scale of the red-noise model, both measured in days. For a 10-day decorrelation time (see below) and consecutive 30-day means, we calculate a lag correlation of 0.22 , smaller than the December-February values of Fig. 4. Note however that even with the observed wintertime values no more than $10 \%$ of the variance of the NAO can be explained by its value in the previous month.

Lag correlations for daily values of the NAO index are shown in Fig. 5. In all seasons the correlations decay to values below 1/e in fewer than 10 days. In the winter, and to some extent in the fall, however, there is a "shoulder" in the lag correlations, a significant deviation from exponential decay at lags of 2-5 weeks. The cause for the lag-correlation shoulder could be the long thermal memory of the upper ocean. Barsugli and Battisti (1998, hereafter B\&B) provide a simple linear model useful for quantifying the role of the upper ocean in enhancing the persistence of atmospheric variability. Their model has two equations, one representing the evolution of atmospheric temperature, $T_{a}$, which could also be seen as an index of a mode of

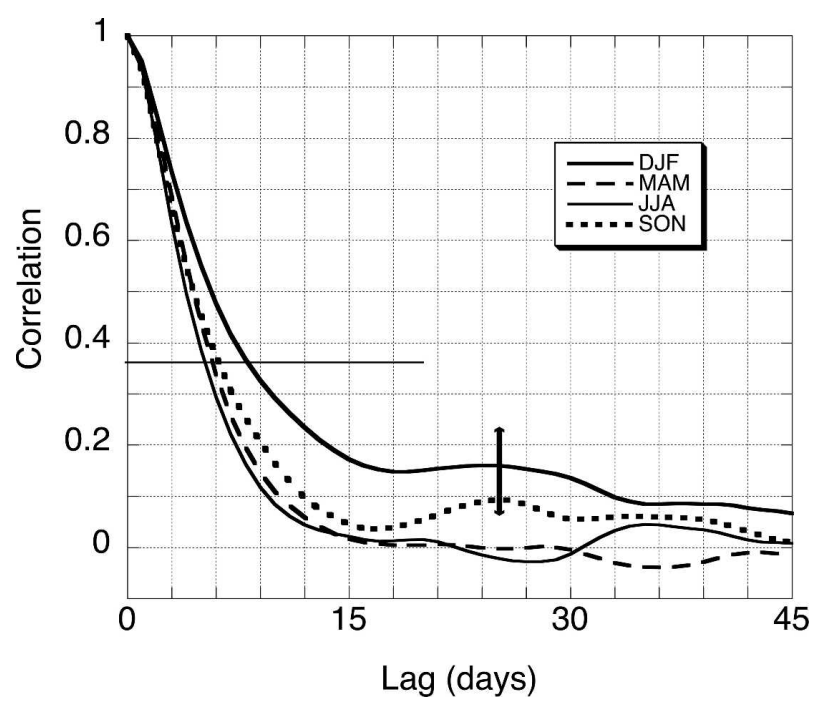

FIG. 5. Autocorrelation of daily NAO index values by season (index data from CPC; see Fig. 3). The heavy vertical line drawn at the "shoulder" is the $95 \%$ confidence interval.

atmospheric variability and the second representing the evolution of the ocean mixed-layer temperature, $T_{o}$, or alternatively the amplitude of a pattern of mixed-layer temperature that interacts with the atmospheric mode (the SST "tripole"; Visbeck et al. 2002). The atmosphere is forced by noise, $N(t)$, associated with the chaotic variability of synoptic systems. The parameters of the $\mathrm{B} \& \mathrm{~B}$ linear model are derived from a long integration with a two-layer, coupled global model.

Two examples of the response of the simple coupled system to atmospheric impulsive forcing are shown in Fig. 6. They show the effect of changing the ocean feedback parameter, $b$ (see $\mathrm{B} \& \mathrm{~B}$ ). Here the atmospheric damping parameter ( $a$ in $\mathrm{B} \& \mathrm{~B})$ has been reduced to a value to 0.6. This gives an initial exponential decay of the atmospheric index on a time scale of less than 10 days, consistent with wintertime observations of the NAO. In the case where there is no ocean feedback on the atmosphere, $b=0$, the exponential decay continues. When the ocean feedback is increased to the largest value at which the system remains stable, $b=1.1$, there is significantly more persistence in the daily values to the end of the month and beyond, somewhat similar to the observed "shoulder" in the winter values of Fig. 5.

The enhanced long-term persistence of daily values, in the case with strong ocean feedback, gives rise to a significant increase in the one-month lag correlations of the atmospheric index, from 0.18 when $b=0$, to 0.31 , when $b=1.1$. This greater value for the persistence is close to what is observed for the winter NAO. Thus it appears that the thermal memory of the ocean mixed 


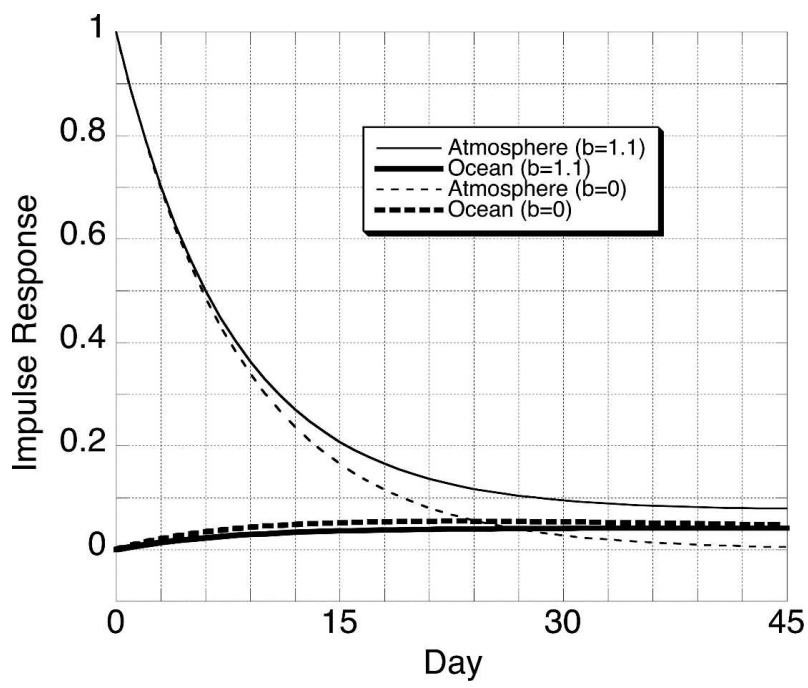

FIG. 6. Impulse response of the Barsugli and Battisti (1998) model in the atmosphere and the ocean for two different values of the coupling parameter, $b$ (see reference for more details).

layer could be responsible for the persistence of the NAO beyond the time scales of atmospheric dissipation. If so, it implies that there is a significant two-way interaction between the atmosphere and the ocean, which could contribute to interseasonal or interannual predictability. This could become useful if ocean temperature anomalies are, as suggested by observational and modeling studies, affected by reemergence. That is, mixed-layer temperature anomalies are created during one cold season, then preserved beneath the shallow seasonal thermocline in the summertime, then "reemerge" during the following cold season (Alexander and Deser 1995; Alexander et al. 1999).

Unfortunately there are reasons to suspect that the ocean is not responsible for the NAO shoulder. To obtain a value of the persistence close to what is observed, the parameters must take on values that are probably unrealistic, because they are barely stable, and because they are quite different from the original values chosen by $\mathrm{B} \& \mathrm{~B}$, based on the integration of a coupled model. Notably, Bretherton and Battisti (2000) found that the $\mathrm{B} \& \mathrm{~B}$ model with the original parameter settings yields excellent agreement with the response of ensemble GCM integrations forced with the historical SST evolution (e.g., Rodwell et al. 1999).

Arguably, if the local interaction with the upper ocean were the source of the month-to-month correlation we would not expect it to change so drastically during the winter-to-spring transition. The significant seasonal changes in month-to-month correlations are more readily understood if they (and by inference the "shoulder") come from the interaction with the strato- sphere, as suggested, for example, by Baldwin et al. (2003b). There are distinct seasonal "windows" for robust stratosphere-troposphere communication, those months when the stratospheric winds are westerly and the flow is sufficiently disturbed to permit strong variability. The rapid breakdown of the decorrelation in March is consistent with the springtime breakdown of the stratospheric polar vortex.

When testing the effect of ocean-atmosphere coupling in state-of-the-art GCMs, which reproduce the observed structure and variability of the NAO, investigators find conflicting evidence regarding the influence of ocean-atmosphere coupling on atmospheric persistence (e.g., Kushnir et al. 2002a). In a recent study using a version of the National Centers for Environmental Prediction medium-range forecast model (Peng et al. 2005) the model greatly underestimates the observed month-to-persistence in the NAO in winter despite its ability to display realistic intraseasonal SST persistence (Fig. 7). Moreover, there is only a small difference in the persistence of the NAO between the coupled and uncoupled models, even though the coupled model does produces a significantly greater midwinter variance in the NAO. It should be noted that while this model has excellent vertical resolution in the troposphere, it does not have a well-resolved stratosphere. In contrast, Bladé (1997), found that coupling with a mixed-layer model enhanced the month-to-month persistence of the leading EOF of 500-hPa heights in her model. It is perhaps relevant, however, that Bladé's experiment was conducted in a perpetual January setting, while the Peng et al. model includes the seasonal cycle. While the role of the ocean in enhancing atmospheric persistence is still debated it is important to remember that the overall effect amounts to $\sim 10 \%$ of the variance.

\section{c. Interannual persistence and predictability of the $N A O$}

Excluding the influence of multiyear climate variability and trends, such as could arise from internal, decadal variations or external forcing, there are several possible sources of intraseasonal to interannual predictability of the NAO:

(i) The underlying North Atlantic Ocean.

(ii) Persistent or predictable elements of the stratospheric circulation.

(iii) Persistent or predictable elements of the land surface-especially snow cover.

(iv) Persistent or predictable behavior elsewhere in the climate system, which can influence the North Atlantic basin remotely. 

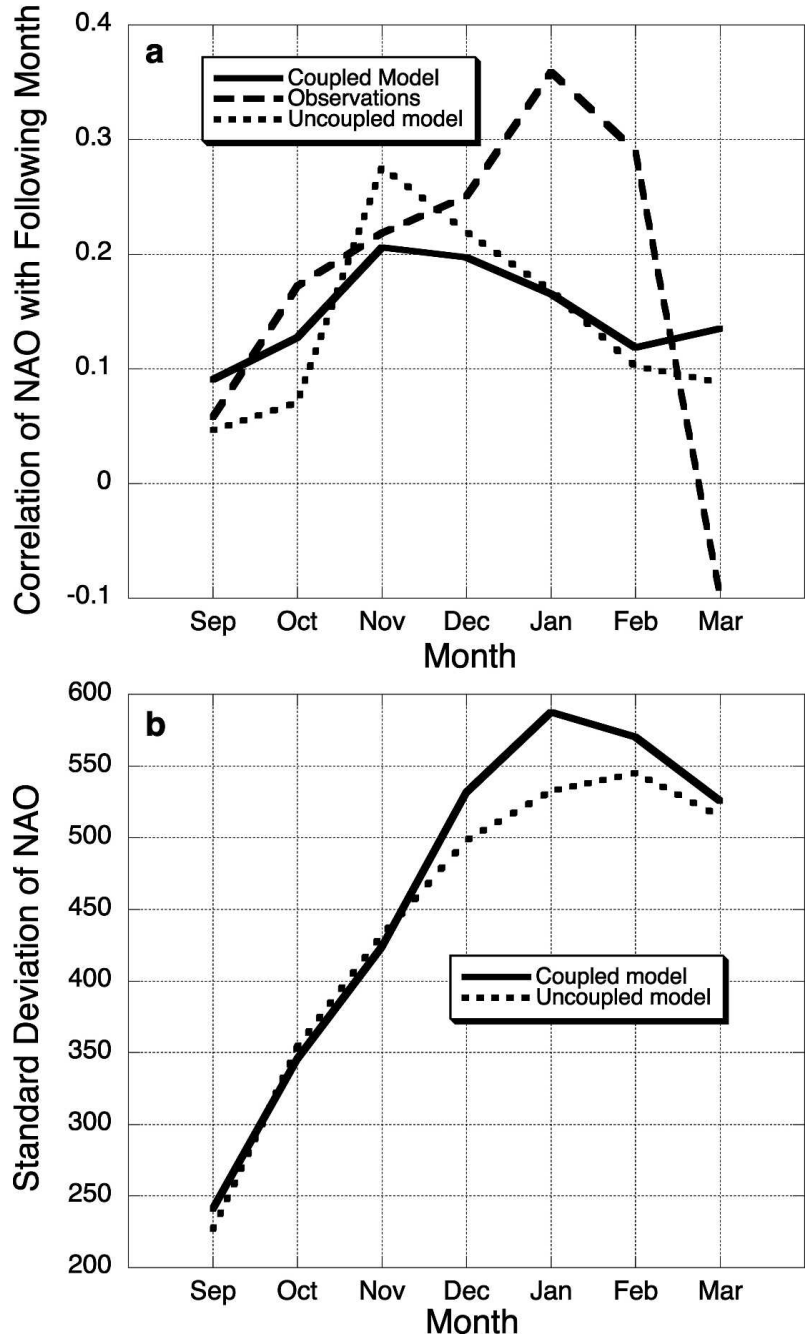

FIG. 7. (a) Month-to-month persistence of the NAO in observations and in a GCM integrated coupled and uncoupled to an ocean mixed layer (Peng et al. 2005). (b) Standard deviation of the monthly mean NAO index in the coupled and uncoupled integrations. Units are $\mathrm{hPa}$.

Two recent studies by Czaja and Frankignoul (2002) and Rodwell and Folland (2002) indicate a role for the North Atlantic Ocean in interannual variability of the NAO. These studies use a lagged singular value decomposition (SVD) analysis between the anomalous SST and 500-hPa geopotential height fields over the Atlantic to determine the patterns of heights and SST with the strongest association at a given time lag. Using observations during the recent half century, Czaja and Frankignoul find that an early winter (NovemberDecember-January) pattern in geopotential height, which strongly resembles the negative NAO, is preceded in summer and fall by a coherent SST pattern with a horseshoe-like band of warm water in the mid- latitude east Atlantic, extending from the subpolar to the subtropical region and enclosing a cold SST anomaly off the east coast of the United States (given their linear analysis, a relationship with opposite phases is also implied). Notably, wintertime atmospheric forcing of the ocean leads to an SST pattern that is often referred to as the "tripole" (Visbeck et al. 2002). The tripole is broadly similar to the horseshoe, but has a more distinct separation between the subpolar and subtropical regions, and the largest SST features are located more to the west (Fig. 8). Rodwell and Folland confirmed these results and show that they are simulated in a GCM forced with observed SST anomalies.

There is copious observational and modeling evidence that the tripole is primarily a result of atmospheric forcing of the SST field associated with the NAO, although models indicate that the tripole can also force the NAO (Seager et al. 2000; Sutton and Hodson 2003; Rodwell and Folland 2002; Peng et al. 2002; Lin and Derome 2003). Czaja and Frankignoul speculate that the summertime "horseshoe" pattern emerges from the tripole pattern after the winter, when atmospheric forcing weakens considerably and oceanic advection and damping reshape the pattern. If so, there is a feedback between ocean and atmosphere on seasonal time scales, which can contribute to a significant interannual persistence of the NAO.

The model of B\&B can again be used to examine this proposition. Imagine that the ocean, represented by a single index denoting the strength of the tripole SST pattern, accumulates a value (i.e., is forced by the atmosphere) over the course of the first winter proportional to a weighted average of the NAO during that winter. This signal is then perfectly preserved over the summer to affect the atmosphere in the following winter, whereupon it decays exponentially on the mixedlayer time scale. As it decays, however, it induces an NAO response in the atmosphere.

Under the assumption that atmospheric variability is primarily intrinsic (i.e., only a small portion is contributed at any time by the SST), the correlation between the NAO acting over a period $T$ throughout the first winter and the tripole index at the end of that period, is given by

$$
C\left(\mathrm{NAO}_{1}, \text { Tripole }\right)=\left(1-e^{-\delta T}\right) / \sqrt{\delta T},
$$

where the mixed-layer damping rate, $\delta$ takes on a numerical value, according to $\mathrm{B} \& \mathrm{~B}$, of $1 / 185 \mathrm{day}^{-1}$. The correlation between the tripole index at the beginning of the second winter and that winter's NAO is given by

$$
C\left(\text { Tripole, } \mathrm{NAO}_{2}\right)=z^{-1} \frac{\left(1-e^{-\delta T}\right)}{\sqrt{\delta T}},
$$




\section{Correlation with Nov-Jan NAO Index}
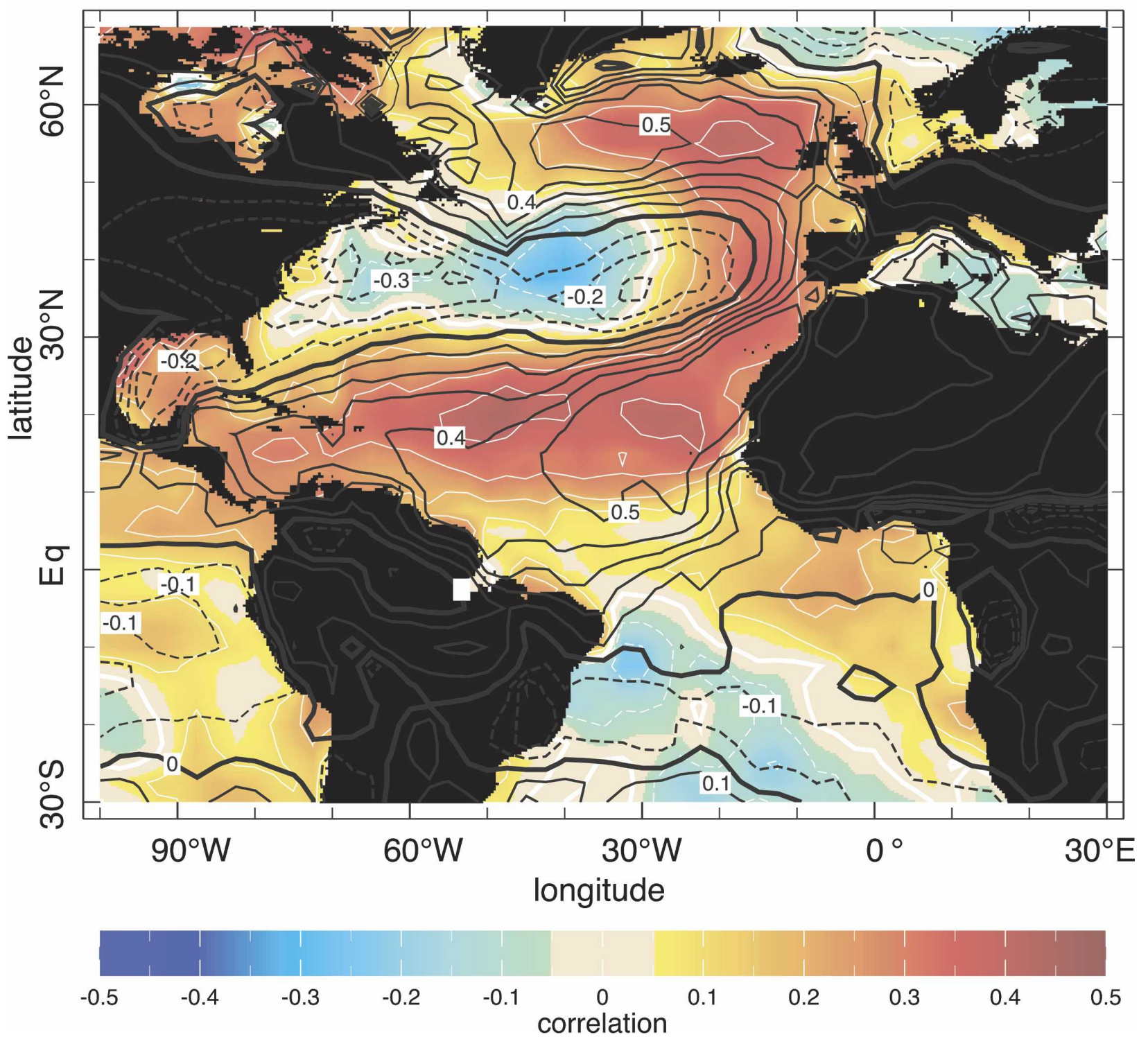

FIG. 8. Correlation between the November-January average NAO index value and the SST field in the preceding July-September ("horseshoe" pattern, in color and white contours, every 0.1) and the SST field in the following December-February ("tripole" pattern, in black contours, every 0.1). Negative contours are dashed and the zero contour is thick. The figure is inspired by the Czaja and Frankignoul (2002) maximum covariance analysis results.

where $z$ is a coefficient representing the ratio between the damping and coupling coefficients in the linear model (in B\&B it is referred to as the stability parameter). The year-to-year correlation of the NAO is then

$$
C\left(\mathrm{NAO}_{1}, \mathrm{NAO}_{2}\right)=\frac{1}{z \delta T}\left(1-e^{-\delta T}\right)^{2}
$$

For the B\&B values of parameters $(z=2.42)$, and averaging the NAO over 3 months, this gives

$$
\begin{aligned}
C\left(\mathrm{NAO}_{1}, \text { Tripole }_{1}\right) & =0.55, \\
C\left(\text { Tripole }_{1}, \mathrm{NAO}_{2}\right) & =0.23, \\
C\left(\mathrm{NAO}_{1}, \mathrm{NAO}_{2}\right) & =0.13 .
\end{aligned}
$$

Here subscripts 1 and 2 refer to the first and subsequent year in the sequence, respectively.

How do these values compare with observations? Table 1 shows correlations of detrended three-month averages of the NAO between consecutive winters. 
TABLE 1. One-year lag autocorrelation of detrended 3-month mean NAO index, calculated for the years 1958-2004. Bold numbers indicate statistically significant values ( $5 \%$ level—two sided).

\begin{tabular}{cccc}
\hline \hline Months & $\mathrm{NDJ}_{2}$ & $\mathrm{DJF}_{2}$ & $\mathrm{JFM}_{2}$ \\
\hline $\mathrm{NDJ}_{1}$ & 0.11 & 0.14 & 0.10 \\
$\mathrm{DJF}_{1}$ & 0.19 & 0.25 & 0.17 \\
$\mathrm{JFM}_{1}$ & $\mathbf{0 . 3 2}$ & 0.26 & 0.09 \\
\hline
\end{tabular}

Note that with values larger than 0.25 and 0.29 , the null hypothesis that there is no correlation from one year to the next can be rejected with $90 \%$ and $95 \%$ confidence (respectively), based on a two-sided parametric test. The season is represented by different three-month averages to identify the times of largest correlation. As it turns out the largest correlation is between late winter of the first year $\left(\mathrm{JFM}_{1}\right)$ and early in the following winter $\left(\mathrm{NDJ}_{2}\right)$. Table 2 shows that the best precursor of the end-of-winter $\left(\mathrm{M}_{1}\right)$ tripole is the state of the NAO throughout the winter, but that the November $\left(\mathrm{N}_{2}\right)$ reemerging tripole is not well correlated with following NAO (the large correlation with NDJ is an overestimate because of the overlapping November). The observed correlation between the $\mathrm{M}_{1}$ tripole and the $\mathrm{N}_{2}$ one is 0.65 . Thus observed $C\left(\mathrm{NAO}_{1}, \mathrm{NAO}_{2}\right)$ values are somewhat larger than predicted by the simple model despite the fact that the NAO-tripole links (reemergence included) suggest a much weaker connection than the observed. Our present results could mean that SST anomalies other than the Atlantic tripole, or other processes altogether, provide year-to-year memory for the NAO.

The hypothesis that a summertime horseshoe anomaly can lead to a late-fall to early-winter NAO was recently tested by Peng et al. (2005), using an atmospheric GCM coupled to a mixed-layer ocean model. They found that the horseshoe is ineffective in forcing the NAO, but that a late summer equatorial Atlantic SST anomaly [also identified as an NAO precursor by Czaja and Frankignoul (2002)] does lead to and NAO pattern in late winter. Moreover, Peng et al. suggest that the evolution of the horseshoe into the tripole, observed by Czaja and Frankignoul, results from the evolution of the response to the equatorial Atlantic SST anomaly. The fall-time atmospheric wave train response to the latter tends to produce the horseshoe SST anomaly, whereas in late winter, once transient-eddy feedback reaches its peak, the equatorial SST anomalies generate the NAO. That, in turn, produces the tripole (Fig. 9). The importance of tropical Atlantic SST as a summertime precursor to early-winter NAO was also noted by others (Robertson et al. 2000; Rodwell 2002; Sutton and Hodson 2003; Cassou et al. 2004).
TABLE 2. Correlation of the 3-month mean NAO index with the tripole index in the following March $\left(\mathrm{M}_{1}\right)$ and the preceding November $\left(\mathrm{N}_{2}\right)$ calculated for the years 1958-2004. Note that in the latter case the $\mathrm{N}_{2}$ to NDJ correlation is an overestimate, affected by the overlap between the 3-month average and November. Both NAO and tripole index values were detrended prior to the calculations. Bold numbers indicate statistically significant values $(5 \%$ level-two sided).

\begin{tabular}{cccc}
\hline \hline Months & NDJ & DJF & JFM \\
\hline $\mathrm{M}_{1}$ & $\mathbf{0 . 2 9}$ & 0.26 & $\mathbf{0 . 3 8}$ \\
$\mathrm{N}_{2}$ & $\mathbf{0 . 3 5}$ & 0.10 & 0.03 \\
\hline
\end{tabular}

It remains unclear what these results imply for interseasonal prediction. Peng et al. forced their atmospheric model with an equatorial SST anomaly that persisted throughout the entire winter-which is an exceptional evolution of the SST field there. It could be hoped that the tripole generated through this atmospheric bridge from the equatorial Atlantic earlier in the winter would persist and then provide forcing of the NAO later in the winter. This would lead to predictability without requiring that the equatorial anomaly persists. While this is a possibility, Peng et al. found that the tripole SST anomalies produced in response to the equatorially forced NAO are on the order of only $0.5^{\circ} \mathrm{C}$. Given a typical model NAO response to the tripole of $20 \mathrm{~m}$ in 500-hPa geopotential height per degree tripole SST anomaly, this suggests that, at most, $10 \mathrm{~m}$ of interannual variability in the NAO is predictable through this pathway, compared with observed interannual variations of more than $80 \mathrm{~m}$ is the northern lobe of the NAO.

Could SST variability outside the Atlantic affect NAO variability? Modeling studies recently suggested that SST in the Indian Oceans could have a significant influence on the NAO (Hoerling et al. 2001, 2004). The work by Hoerling et al. (2001, and subsequent papers) may be applicable only to the observed, long-term trend in the NAO rather than to interannual variability. Figure 10 shows the global SST pattern that simultaneously varies with the wintertime NAO during 19582004, and, for comparison, the SST patterns in the preceding and following seasons. There is little indication here of remote influences. In the North Atlantic the tripole pattern is evident, primarily a result of atmospheric forcing of the ocean.

\section{$d$. The role of the stratosphere}

Evidence is accumulating that the strength of the boreal stratospheric polar vortex influences the tropospheric circulation on intraseasonal time scales, especially the NAM, which is well correlated with the NAO. 
a) $\operatorname{Oct}-\operatorname{Dec}(P-C)$

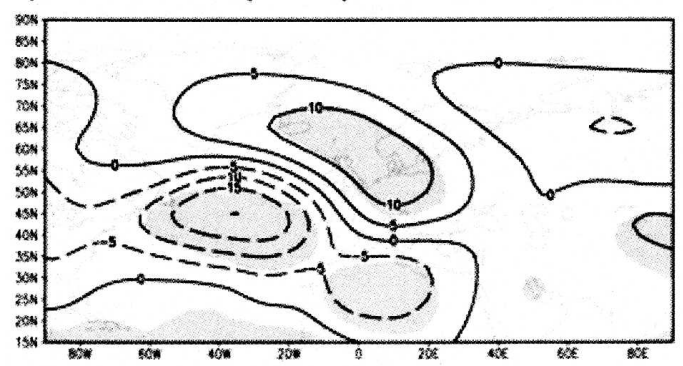

a) $\operatorname{Oct}-\operatorname{Dec}(P-C)$

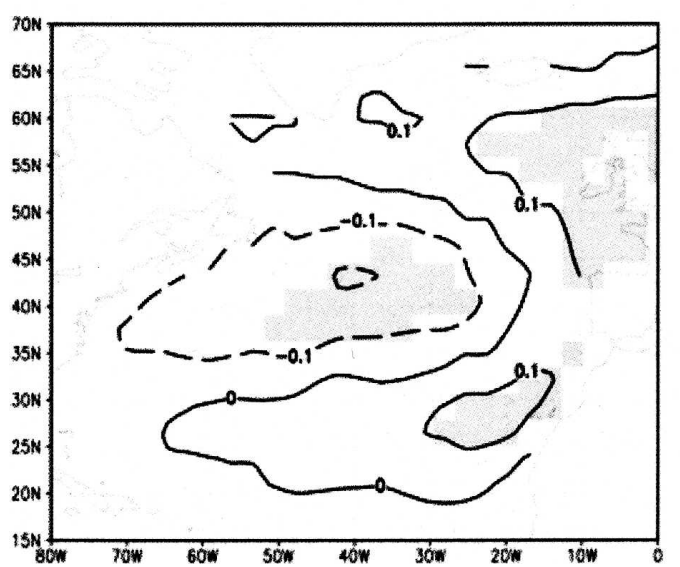

b) $\mathrm{Feb}-\operatorname{Apr}(\mathrm{P}-\mathrm{C})$

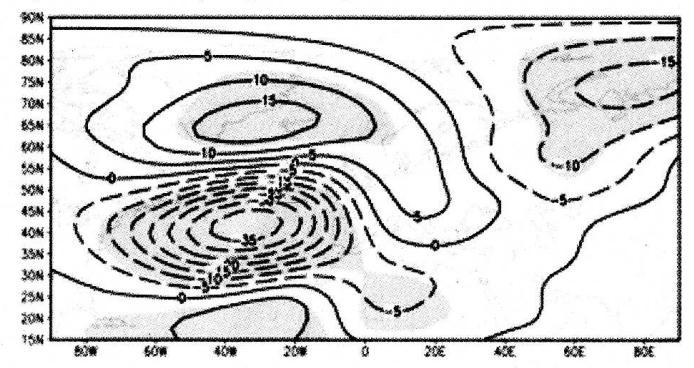

b) $\mathrm{Feb}-\operatorname{Apr}(\mathrm{P}-\mathrm{C})$

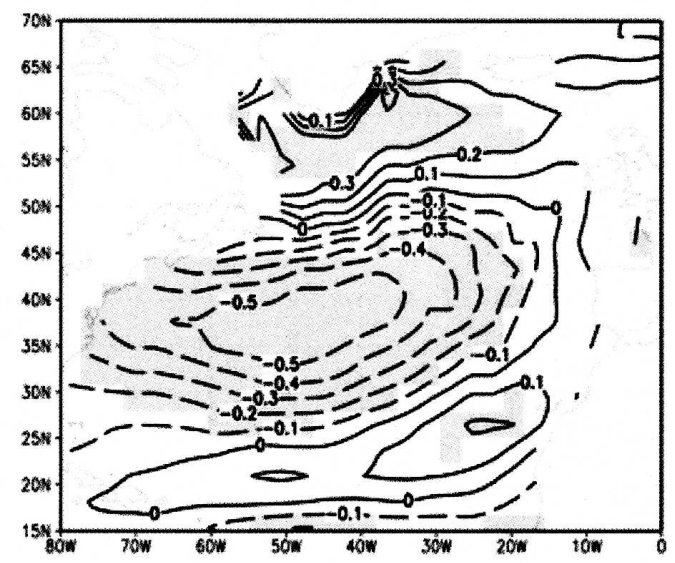

FIG. 9. (left) Early- and (right) late-winter responses to a warm equatorial Atlantic SST anomaly prescribed in an atmospheric model coupled to an extratropical ocean mixed layer. (top) The 500-hPa geopotential response (contour interval of $5 \mathrm{~m}$ ) and (bottom) the SST response (contour interval of $0.1 \mathrm{~K}$ ). (From Peng et al. 2005.)

Because the polar vortex exhibits dynamical memory over tens of days, such stratospheric influences can extend the persistence of the NAM or NAO (Baldwin et al. 2003a) during mid- to late winter, when there is strong dynamical coupling between the troposphere and stratosphere. Hence the suggestion made earlier in this paper, that the stratosphere is responsible for the "shoulder" in the lagged autocorrelation of the NAO. The dynamical mechanisms for this downward influence are not entirely understood (Kushner and Polvani 2004; Song and Robinson 2004), but presumably involve the downward closing secondary circulations induced by anomalous stratospheric wave driving (Haynes et al. 1991), altered planetary wave propagation (Chen and Robinson 1992; Limpasuvan and Hartmann 2000; Perlwitz and Harnik 2003), tropospheric transient-eddy feedbacks (Song and Robinson 2004), and possibly planetary-scale baroclinic waves (Tanaka and Tokinaga 2002).

At first glace, it seems unlikely that the stratosphere can contribute to S/I predictability, since the polar vortex is coupled to the troposphere only during the win- ter. The summertime reversal of stratospheric winds effectively "resets" the flow, and memory within the stratosphere from one winter to the next is not expected. There are, however, phenomena through which the stratosphere may provide some interseasonal or interannual predictability. Foremost among these is the quasi-biennial oscillation (QBO) of the equatorial stratosphere. The QBO, an internal nonlinear oscillation of the atmosphere, is unique among modes of atmospheric variability in that it is nearly periodic - with an average period of about 28 months-and is therefore predictable (Baldwin et al. 2001). The two pieces that comprise a possible QBO influence on the NAO are the influence of the polar vortex on the NAO, discussed above, and the influence of the QBO on the polar vortex. That the QBO influence the strength of the polar vortex was demonstrated by Holton and Tan (1980). They found that the latter is weaker when the equatorial stratospheric zonal winds are more easterly. Their suggested explanation for this relationship was later confirmed in a numerical modeling study (O'Sullivan and Salby 1990). When the QBO winds are easterly, the 

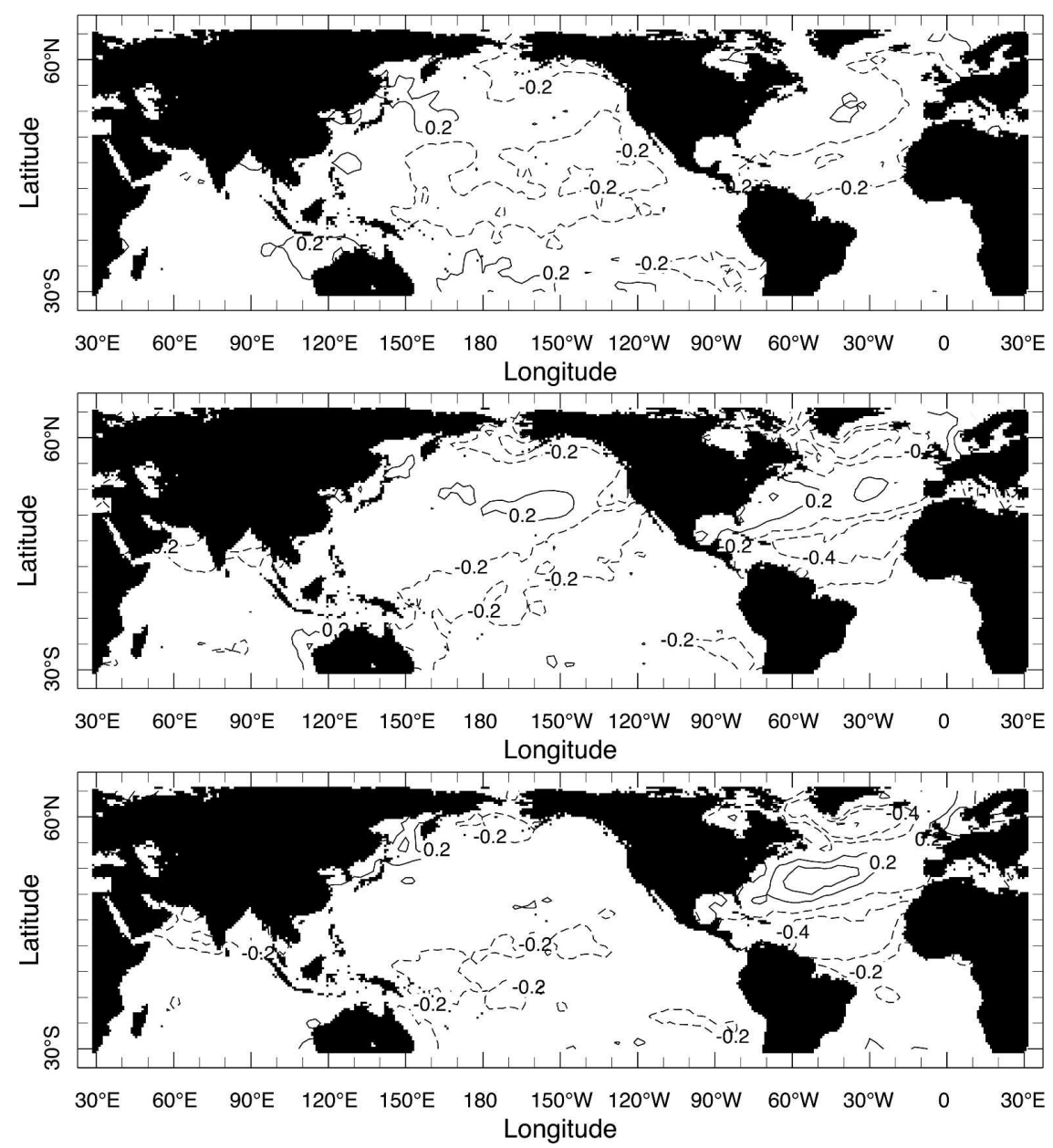

FIG. 10. Correlation between the detrended December-February NAO index and the (top) fall (September-October), (middle) winter (December-January), and (bottom) spring (March-May) global SST field, 1958-2004.

critical line for quasi-stationary planetary Rossby waves shifts poleward. Through nonlinear critical-layer reflection this concentrates the planetary wave activity in high latitudes, leading to a weakening of the polar vortex. The opposite is true for the westerly phase of the QBO, which leads to a strong polar vortex.

This plausible physical link between the equatorial QBO and the NAO is also seen in observations. Figure 11 (after Baldwin et al. 2001) shows the regression and correlation of sea level pressure during winter with the QBO index. ${ }^{4}$ The regression exhibits the expected low heights over the Arctic and positive height anomalies in lower latitudes, with a significant projection on the NAO pattern. Consistent with this result is the large

\footnotetext{
${ }^{4}$ Index data derived from NCEP-NCAR reanalysis by C. Smith at CDC: http://www.cdc.noaa.gov/ClimateIndices/Analysis/ \#QBO.
}

power found in the NAO spectrum in the quasibiennial band (Hurrell et al. 2002).

The contribution of the QBO to the interannual variability of the NAO is, however, modest. The correlation between the QBO (defined by 30-hPa equatorial zonal winds) and the December-January-February average of the NAO index over the period 1950-2000 (with the trend in the NAO removed) is 0.22 - the positive sign of the correlation being consistent with dynamical expectations and Fig. 11. It is important to add here that the QBO influence will tend to reverse the NAO phase from one winter to the next. While increasing the interannual predictability of the NAO, the QBO actually weakens the interannual persistence of the former. Thus, in the presence of the QBO, the interannual persistence of the NAO (discussed in section $3 c$ above) becomes even harder to explain.

Another phenomenon with significant predictive 

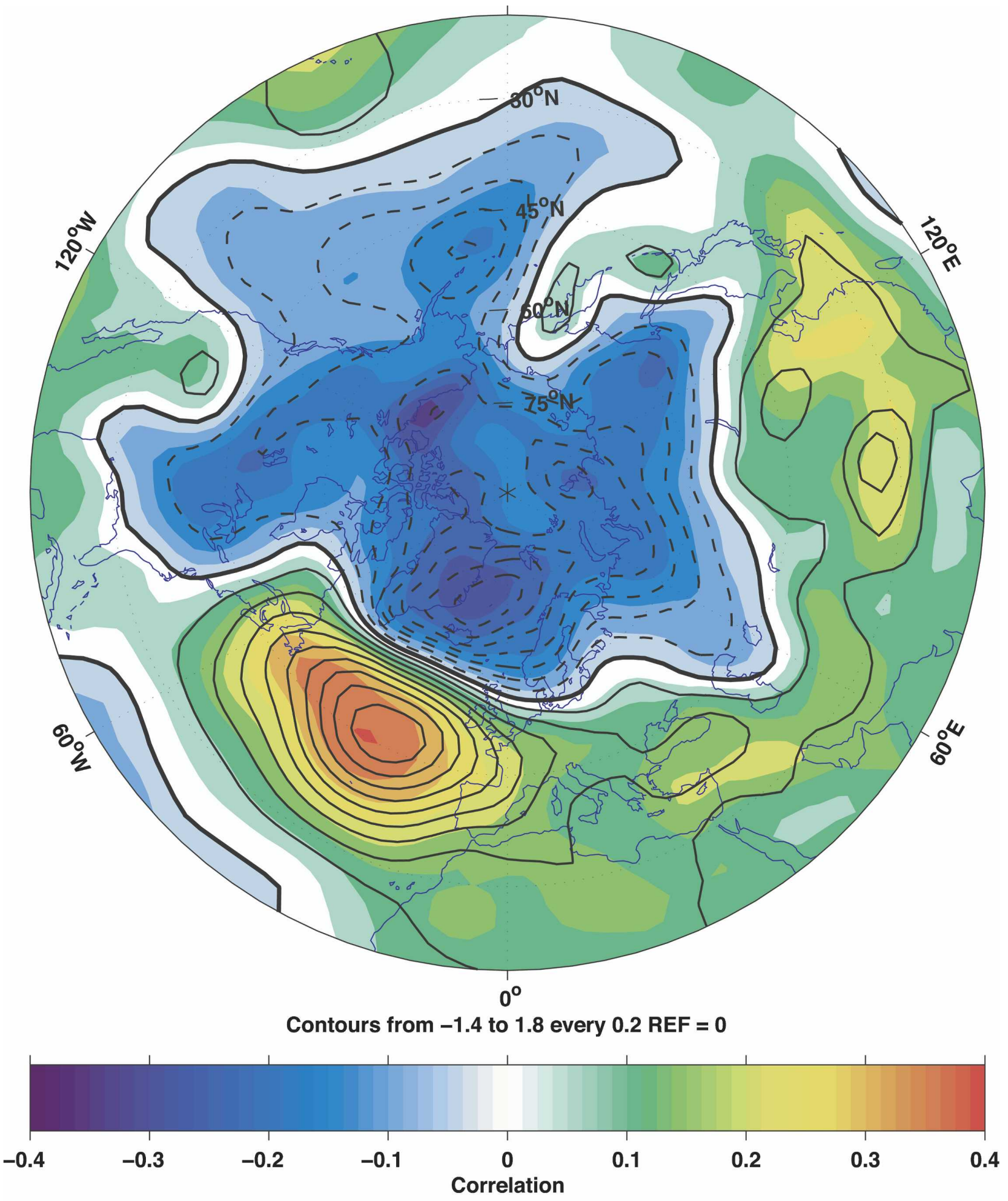

FIG. 11. Regression (contours) and correlation (colors) of the wintertime (December-February) sea level pressure data (from NCEP-NCAR reanalysis) on the QBO index, 1958-2004. 
power for the NAO, albeit at rare intervals, is the occurrence of an explosive tropical volcanic eruption (Robock 2000), the best-studied case being that of Mt. Pinatubo in 1991. As for the QBO, volcanic eruptions affect the stratospheric polar vortex, and this influence is again transmitted downward dynamically to the NAO. The sulfate aerosol that forms in the stratosphere following an explosive eruption warms the lowlatitude stratosphere by absorbing upwelling terrestrial infrared and solar near-infrared radiation. Since there is less anomalous radiative heating of the polar winter stratosphere, the equator-to-pole temperature contrast is strengthened, thus strengthening the polar vortex. This leads to an enhancement of the NAO in the winters following an eruption. An interesting wrinkle on this (Stenchikov et al. 2004), at least in a general circulation model, is that the influence of the eruption combines nonlinearly with that of the QBO, so that the strengthening of the NAO in the winter following an eruption will be significantly greater if that winter is in the westerly phase of the QBO.

A final possible role for the stratosphere comes, surprisingly, in explaining the observed relationship between fall snow cover over Eurasia and the NAO in the following winter. It is observed (Cohen and Entekhabi 1999) that fall seasons with anomalously extensive snow cover in Eurasia are followed by winters with a positive NAO. While it might be expected that this is a manifestation of atmospheric persistence or of an evolving influence from remote SST anomalies, two recent papers (Gong et al. 2003, 2004) make the case that Siberian snow-cover anomalies perturb the orographic generation of vertically propagating planetary waves, and thus influence the strength of the stratospheric polar vortex. One problem with this mechanism, however, is that influences from the stratosphere must act in the mid- to late winter, not the fall. The thermal forcing associated with the snow-cover anomalies does indeed persist through the winter in the Gong et al. general circulation model experiments, because they associated snow-cover anomalies with snow-depth anomalies, and the snow is added or removed over the course of the winter to maintain the anomalous snow depth. Thus, anomalous planetary wave forcing associated with the resulting thermal anomaly acts over the course of the winter, when the dynamics permit both variations in the strength of the polar vortex and its subsequent downward influence. The question that must be addressed, in order to assess the practical relevance of the Gong et al. results, is whether in nature, fall snow-cover anomalies lead predictably to significant wintertime anomalies in the surface thermal budget.

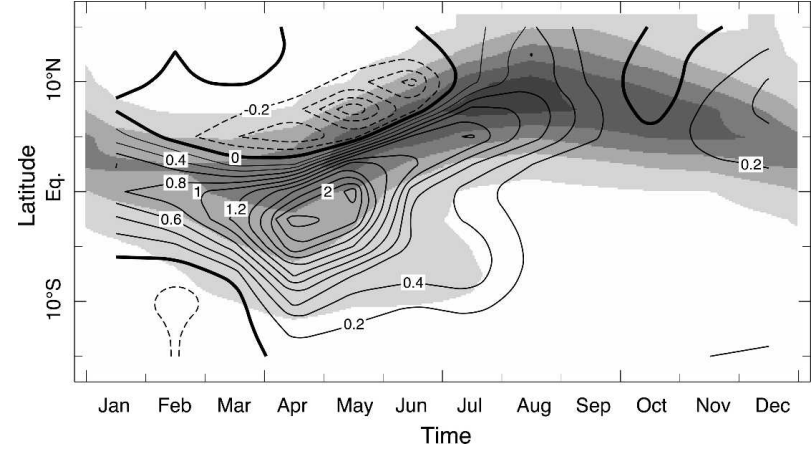

FIG. 12. Tropical Atlantic ITCZ rainfall, averaged between $35^{\circ}$ and $15^{\circ} \mathrm{W}$ as a function of latitude and calendar month. Gray shaded is the climatological mean, 1979 to 2001 (shaded in steps of $2 \mathrm{~mm}$ day $^{-1}$ with values less than 2 in white). Contours are for the first EOF (30\% of variance explained) of the year-to-year variations of rainfall in the same region, depicting the seasonal changed in the variability. Contour interval is 0.2 with negative contours dashed and thick zero contour.

\section{Climate predictability in the tropical Atlantic}

\section{a. Background}

The most important indicator of tropical Atlantic (TA) climate variability are the fluctuations in rainfall over the surrounding land regions and the related changes over the ocean, within the marine ITCZ. Figure 12 depicts the variability in TA ITCZ rainfall in relation to its mean annual cycle. The figure shows the changes in ITCZ position and intensity as a function of the calendar month. On average, the Atlantic ITCZ moves between the equator and $\sim 8^{\circ} \mathrm{N}$, reaching its farthest south in April and farthest north in August (see also Mitchell and Wallace 1992). Maximum rainfall intensity in the ITCZ occurs during the boreal summer. The variability in ITCZ position and intensity is depicted in Fig. 12 by the first EOF of longitudinally averaged TA rainfall in the calendar month-latitude space. This EOF explains $30 \%$ of the total variance in this space. The largest variations in the rainfall occur during the boreal spring, when the ITCZ is farthest south. The EOF pattern implies the southward amplification (or lack thereof) of the ITCZ during its closest approach to the equator. An examination of the longitudinal distribution of these changes reveals that they are strongest on the western side of the basin over the South American seaboard (see Fig. 15a).

Atlantic ITCZ variability is closely tied to two sources of forcing: El Niño and the anomalous distribution of SST within the tropical Atlantic (Chang et al. 2000; Saravanan and Chang 2000; Sutton et al. 2000). Other variables that affect society in this region are tropical storm activity, surface temperature, and lower- 


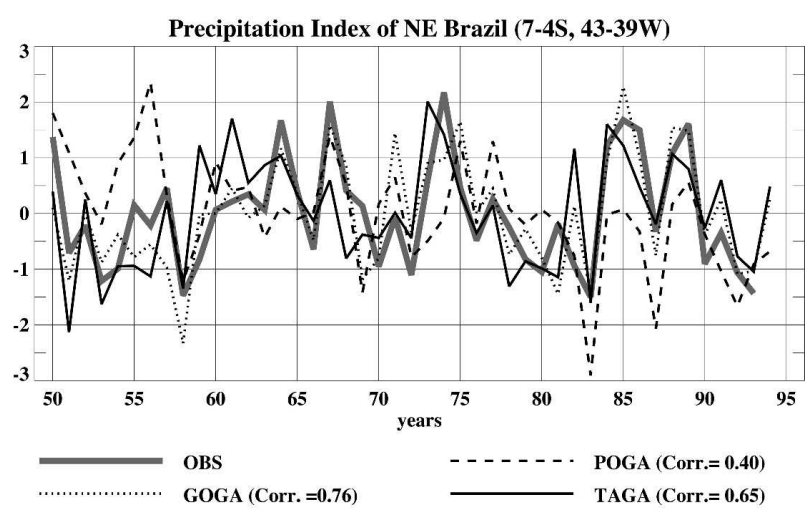

FIG. 13. Simulated and observed NE Brazil rainfall index. Simulations are based on the NCAR CCM3 forced by observed SST in various ocean basins. Thick solid: observation. Dotted: global SST forcing (GOGA). Dashed: tropical Pacific-only SST forcing (POGA). Thin solid: tropical Atlantic-only SST forcing (TAGA).

troposphere dust burden. These are closely related to the rainfall variability and also affected by El Niño and by SST (Fontaine and Bigot 1993; Goldenberg and Shapiro 1996; Shapiro and Goldenberg 1998; Giannini et al. 2003).

Climate models forced with observed, global SST variability simulate quite successfully the associated variations in tropical Atlantic rainfall (Goddard and Mason 2002). As an example of the roles of El Niño and local SST in TA rainfall, Fig. 13 displays a comparison between an observed and $\mathrm{GCM}^{5}$ simulated index of Nordeste (in northeast Brazil) rainfall during boreal spring March-April-May (MAM; see also Figs. 1 and 2). When global SSTs from 1950 to 1994 are used to force the model [an experiment dubbed Global OceanGlobal Atmosphere (GOGA)], the simulated rainfall index (dotted line) tracks the observed index (thick gray line) and the correlation between the two is 0.76 . When only tropical Pacific SST variability is specified, and SSTs in other ocean basins are kept at their climatological values [the Pacific Ocean-Global Atmosphere (POGA) experiment], the correlation between the observed and simulated indices (dashed line) drops below 0.4 , indicative of the ability of El Niño to influence the TA through an atmospheric connection (Klein et al. 1999). Finally, when only tropical Atlantic SST variability is specified [the Tropical Atlantic-Global Atmosphere (TAGA) experiment], the correlation between the observed and simulated (black line), 0.65 , is almost as high as in the GOGA experiment. This suggests that

\footnotetext{
${ }^{5}$ The atmospheric general circulation model used here is the Community Climate Model version 3.6.6 (CCM3) developed at NCAR in Boulder, Colorado.
}

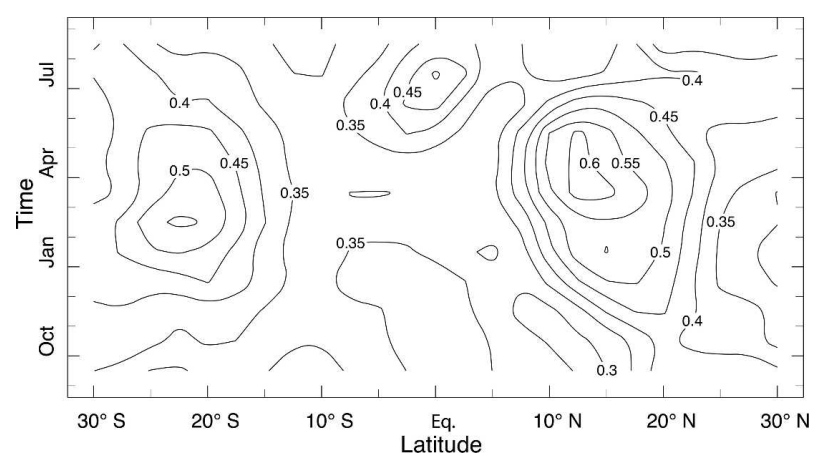

FIG. 14. Root-mean-square SST variability in the tropical Atlantic region, $30^{\circ} \mathrm{S}$ to $30^{\circ} \mathrm{N}$ by latitude and calendar month. The SST anomalies 1949-2004 were first averaged in longitude between $40^{\circ} \mathrm{W}$ and the Greenwich meridian. Data from the Hadley Centre HadISST.

information on SST anomalies in the tropical Atlantic Ocean is crucial for seasonal climate forecasting in the region. However, as described below, TA SST anomalies are a product of external and internal influences, including El Niño.

\section{b. Patterns and mechanisms of tropical Atlantic SST variability}

From the perspective of SST variability, we identify two major TAV patterns with relevance for climate prediction: hereafter referred to as the gradient and equatorial "modes" (Hastenrath 1978; Servain 1991; Ruiz-Barradas et al. 2000; Sutton et al. 2000). A recent review by Xie and Carton (2004) provides an excellent summary of the characteristics of TAV. Here we address these briefly to provide a background to understanding TAV predictability.

\section{1) The GRAdient MOde}

This is a basinwide pattern of interannual variability in the large-scale, meridional temperature gradient between the northern and southern trade wind regions. Variations in this gradient are large from January through May and small in boreal fall (Fig. 14). They arise from variations of SST in the northern and southern trade wind regions, with the former somewhat stronger than the latter (Fig. 14; Nobre and Shukla 1996). The pattern associated with these variations (Fig. 15a) is often portrayed as a dipole (Servain 1991; Nobre and Shukla 1996) but the actual SST variations in the two trade regions do not display an instantaneous negative correlation (Houghton and Tourre 1992; Enfield et al. 1999; Hastenrath 2002). A possible interpretation of this inconsistency is that the meridional SST gradient Rainfall is affected by variations of opposite sign either 

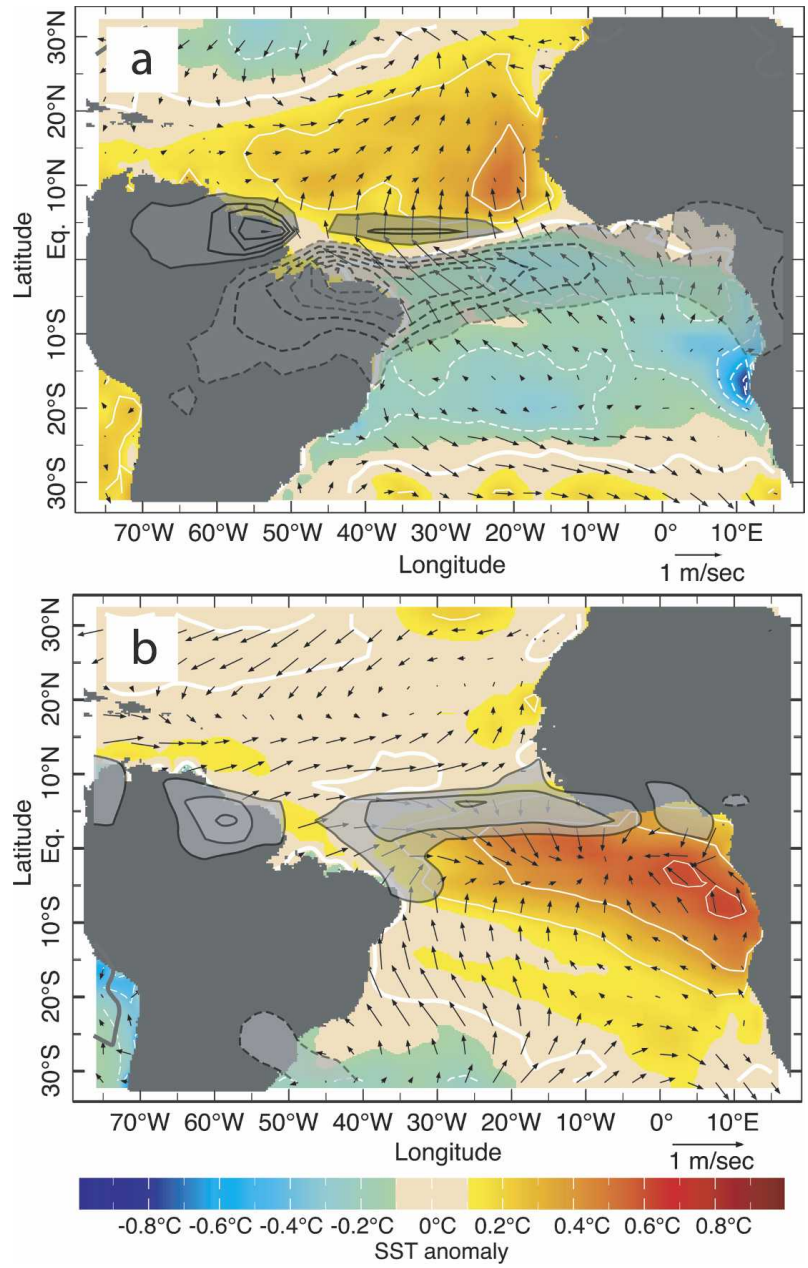

FIG. 15. The dominant pattern of surface ocean-atmosphere variability in the tropical Atlantic region during boreal spring. The gray contours depict the first EOF of the regional rainfall anomaly (from GPCP data, 1979-2001) in $\mathrm{mm} \mathrm{day}^{-1}$. Contours every 0.5 , negative contours are dashed, and the 0 contour is omitted. The colored field is the associated SST anomaly, derived by regression analysis. Units are ${ }^{\circ} \mathrm{C}$ (see scale below; white contours every $0.2^{\circ}$ are added for further clarity). Arrows depict the associated seasonal surface wind anomaly in $\mathrm{m} \mathrm{s}^{-1}$ (arrow scale below frame). (a) Boreal spring (March-April); percent variance explained is 33. (b) Boreal summer (June-August); percent variance explained is 23 .

north or south of the equator and hence the statistical analysis of the data leads to an apparent dipole pattern.

The sensitivity of rainfall variability to the gradient changes is largest in the boreal spring (Moura and Shukla 1981; Nobre and Shukla 1996; Chiang et al. 2002) and is associated with large anomalies in the cross-equatorial flow in the lower troposphere (Nobre and Shukla 1996; Ruiz-Barradas et al. 2000; Saravanan and Chang 2004). The rainfall anomaly associated with this a positive SST gradient anomaly (Fig. 15a) implies a weakening of the ITCZ on its equatorward side, due in part to a failure to reach its normal southmost position during the boreal spring.

Observational and modeling evidence indicates that the gradient mode can be caused by forcing from outside of the tropical Atlantic region, primarily El Niño and the NAO, which affect the strength of the trade winds and, through air-sea heat flux variations, the SST (Enfield and Mayer 1997; Saravanan and Chang 2000; Seager et al. 2001; Chiang et al. 2002; Czaja et al. 2002). These remote influences can interfere with one another and with local feedbacks (Giannini et al. 2004). El Niño influences the region via the atmospheric response to the large perturbation it causes in convective heating over the equatorial Pacific. Well recognized is the stationary wave perturbation it creates over the Northern Hemisphere, which influences the strength of the North Atlantic trades and thus the underlying SST (Hastenrath et al. 1987; Enfield and Mayer 1997; Huang and Shukla 1997; Saravanan and Chang 2000). A more recently discovered influence acts more directly on the Atlantic ITCZ and is related to the spreading of the associated Pacific tropospheric warming signal via tropical wave mechanisms and the resulting stabilization of the tropical atmosphere over the Atlantic (Klein et al. 1999; Hastenrath 2000; Saravanan and Chang 2000; Chiang et al. 2002; Chiang and Sobel 2002; Neelin et al. 2003). Of these two effects, the direct atmospheric response appears earlier in the El Niño cycle, in boreal winter, while the change in the trade region SST appears in the spring (Saravanan and Chang 2000; Chiang et al. 2002), possibly due to the time scale of the upperocean response. The NAO affects the gradient mode through its direct influence on the strength of the Azores anticyclone and the Northern Hemisphere trades during winter in roughly the same region affected by El Niño (Seager et al. 2000; Visbeck et al. 2002). South Atlantic climate variability could also be important acting in a similar way to the NAO but perturbing the Southern Hemisphere trades (Barreiro et al. 2004). Thus, addressing the predictability of climate variability in the tropical Atlantic requires addressing the predictability of El Niño, the NAO, and the much less understood South Atlantic region.

The gradient mode involves a positive thermodynamic feedback between the change in the surface winds in the vicinity of the equator and the change in underlying SST. When a cross-equatorial, meridional wind anomaly arises in response to the anomalous SST gradient-blowing toward the anomalously warmer hemisphere-the related zonal wind anomaly interacts with the prevailing trades to create changes in the wind speed that sustain the existing SST anomaly (Has- 
tenrath 1984; Nobre and Shukla 1996; Kushnir et al. 2002b). Xie (1999) referred to such feedback as a windevaporation-SST (WES) feedback in a study of the equatorial Pacific variability. Saravanan and Chang (2004) studied the WES feedback on the Atlantic gradient mode and showed that it significantly enhances the persistence of the cross-equatorial, meridional wind anomaly and in consequence, that of the SST gradient anomaly.

The role of ocean dynamics in regulating tropical Atlantic SST anomalies associated with the gradient mode is less well resolved. A number of recent modeling studies (Chang et al. 2001; Seager et al. 2001) suggest that meridional ocean heat transport associated with the mean circulation in the tropical Atlantic tends to counteract the near-equatorial WES feedback and weaken the anomalous cross-equatorial SST gradient in the boreal spring.

\section{2) The equatorial mode}

This is a pattern of an eastern equatorial Atlantic SST anomaly, in the "cold tongue" region (Mitchell and Wallace 1992), which peaks in the boreal summer (Figs. 14 and 15b). The SST anomaly is tied with an equatorial wind anomaly depicting convergence toward the warm water (or vice versa in the case of a cold anomaly). The equatorial mode (Zebiak 1993; Carton and Huang 1994; Ruiz-Barradas et al. 2000) bears a certain resemblance to the eastern equatorial Pacific expression of the El Niño-Southern Oscillation phenomenon. The Atlantic equatorial mode is associated with a precipitation anomaly just south of the mean position of the summertime marine ITCZ, indicating intensification over its southern flank when the cold tongue is weaker than normal and vice versa (Fig. 15b).

In the Pacific, the phenomenon is explained primarily by the so called Bjerknes mechanism, in which upper-ocean wave dynamics changes the depth of the thermocline to affect the SST field, which interacts positively with a thermally direct, baroclinic atmospheric response to create a growing disturbance (Bjerknes 1966). It is possible that a similar mechanism is responsible for the Atlantic equatorial mode (Zebiak 1993; Huang and Shukla 1997). However, Zebiak (1993) noted that the properties of the Atlantic climatological mean field and ocean basin configurations affect the properties of the phenomenon, such as inhibiting self-sustained oscillations.

The two tropical Atlantic modes are not necessarily independent of one another. Recent studies find a connection between them in ocean observations of the last $20 \mathrm{yr}$ and in an ocean model based on forcing data from the same period (Servain et al. 1999, 2000). This rela- tionship appears, however, to be absent during the 1950s to 1970s (Murtugudde et al. 2001).

\section{c. Predictability of TAV}

Goddard and Mason (2002) provide an analysis of the effect of SST-specification errors on the errors in rainfall prediction within the tropical Atlantic region, in the context of a two-tiered prediction system. They show that errors in predicted spring rainfall are largest over northeastern Brazil and are linked with an error in specifying the SST gradient across the equator. In the summer, the precipitation forecast errors are largest over West Africa and are linked with an error in specifying SST along the equator.

There is a clear link between the error patterns derived by Goddard and Mason and the patterns of TAV described in the previous section. The errors in rainfall are due to errors in correctly predicting the underlying dominant patterns of SST variability, which can be viewed as forcing the location and intensity of the marine ITCZ and its influences over the African and South American seaboards. The obstacle to predicting rainfall in the tropical Atlantic can thus be linked to an inability to predict SST in the basin (cf. Fig. 13).

In the two-tiered study of Goddard and Mason the SST "forecast" was based on persisting the observed initial conditions. The disadvantage of such methodology is emphasized in Chang et al. (2003) and Saravanan and Chang (2004). They recently showed that the WES feedback in the north TA leads to useful SST predictability if a coupled model is used. They integrated an atmospheric GCM coupled to a global motionless, slab ocean model initiated with observed December SST and followed the coupled evolution for 9 months. Using repeated simulations for the years 1959 to 1997, the average performance in predicting SST in the region bounded by the latitudes $9^{\circ}$ and $21^{\circ} \mathrm{N}$ longitudes $76^{\circ}$ and $26^{\circ} \mathrm{W}$ outperforms persistence already at a lead time of 2 months and maintaines a correlation of 0.5 and higher to the observations up to 8 months. The results were less impressive if the atmosphere-ocean coupling was limited to the Atlantic only, indicating that much of the prediction skill arises from the influence of ENSO on the Atlantic. These remarkable results remain to be tested in actual forecasts. Of particular concern is the influence of the largely unpredictable effect of the Atlantic extratropics, north (e.g., NAO) and south of the equator (Giannini et al. 2004).

The predictability of equatorial SST variability is less well studied. Despite the evidence for the presence of a Bjerknes mechanism in the Atlantic, the properties of the so-called Atlantic Niño are different from its Pacific counterpart (Zebiak 1993). Particularly striking is the 
short duration of the associated cold tongue SST anomalies (see the duration of the equatorial rms SST maximum in Fig. 14). By and large, equatorial Atlantic variability appears to be an internal Atlantic phenomenon (Huang et al. 2002) and hard to predict. That said, there is evidence that ENSO can trigger the appearance of an equatorial Atlantic SST perturbation by forcing a change in the prevailing surface wind stress field in the western equatorial Atlantic (Latif and Barnett 1995). This could lead to useful predictability, but the effect is inconsistent and not always observed.

\section{d. A few comments on South Atlantic climate variability}

There is emerging interest and research into the predictability of seasonal to interannual variability in the South Atlantic. Statistically, the tropical Atlantic equatorial mode extends southward along the lower Guinea coast, where it represents fluctuations in the strength of the seasonal cold SST pattern. Changes in that region are often dubbed "Bengula Niños" and play an important role in interannual precipitation variations over Africa. The potential influence of tropical southeast Atlantic SSTs on Angolan and Namibian rainfall has been studied by Hirst and Hastenrath (1983) and Nicholson and Entekhabi (1987). More recently, Rouault et al. (2002) have drawn attention to the influence of southeast Atlantic warm events on not just the coastal rainfall of tropical southwestern Africa but also, on occasion, over a much larger region of southern Africa. The southern pole of the gradient mode of TAV appears to play an important preconditioning role for the impact of ENSO on northeast Brazil rainfall during the February-May rainy season (Giannini et al. 2004).

Ocean-atmosphere interaction over the subtropical South Atlantic is dominated by variability in the strength and position of the subtropical (St. Helena) anticyclone, together with dipolar SST anomalies with a nodal line near $30^{\circ} \mathrm{S}$ (Venegas et al. 1997). The variability of SST tends to peak in austral summer-fall (Venegas et al. 1997). Evidence, both observational (Venegas et al. 1997; Sterl and Hazeleger 2003) and from models (Haarsma et al. 2003), indicates that anomalous winds generate the SST pattern through anomalous latent heat fluxes and mixed-layer deepening. Anomalous Ekman transports appear to play a secondary role. There is observational evidence that this mode of covariability influences the tropical Atlantic equatorial mode during the austral winter (Robertson and Mechoso 2003) and the gradient mode during the austral fall (Barreiro et al. 2004).

The South Atlantic convergence zone (SACZ) presides in the southwest South Atlantic atmosphere and ocean. The SACZ is characterized by strong intrinsic variability on subseasonal time scales that projects onto the interannual time scale as "climate noise." Variability of the SACZ in the atmosphere is also linked to the underlying ocean, where again the dominant influence is of the atmosphere forcing the ocean (Barreiro et al. 2002; Robertson and Mechoso 2003). The South Pacific also exerts a strong influence on the SACZ through the Pacific-South American (PSA) teleconnection patterns (Mo and Paegle 2001). ENSO influences the SACZ during austral spring (Cazes-Boezio et al. 2003) and may influence the southwest Atlantic through this mechanism (Mo and Hakkinen 2001).

This myriad of phenomena, most of which forced by atmospheric variability, does not bode well for prediction within the South Atlantic basin. However, the related SST anomalies display a modest amount of persistence such that they can carry information from one season into the next (Goddard and Mason 2002). This can be helpful in the TA region where predicting rainfall during the active season (e.g., boreal spring and summer; see sections $4 \mathrm{a}$ and $4 \mathrm{~b}$ ) can benefit from knowledge of subtropical South Atlantic SST in the previous season. This aspect of TA prediction is explored in Barreiro et al. (2004) who conclude, based on a coupled GCM (atmosphere coupled to a slab ocean model) that initial South Atlantic SST conditions from two seasons in advance lead TA SST anomalies in the critical season of boreal spring. This potential for predictability appears to arise from a WES feedback in the south TA. However, these results have not yet been tested in a rigorous prediction study.

\section{Conclusions}

A broad-brush view of large-scale S/I climate anomalies in the Atlantic suggests they can be divided into three types: internal to the basin are extratropical fluctuations driven by atmospheric chaotic dynamics that are to first order insensitive to surface anomalies, and tropical variability where the atmosphere is sensitive, even coupled, to surface conditions, particularly SST variability, and is thus potentially predictable. The third kind is anomalies forced from outside the basin, particularly from the equatorial Pacific.

In the Northern Hemisphere during the last half century, the NAO displayed greater persistence from one winter to the next than is indicated by coupled GCMs and by a simple linear model that has shown remarkable success in explaining the results of SST-forced GCM integrations. The source of this persistence remains unclear. Observations show a link to North Atlantic SST, and some forced GCMs point at the par- 
ticular importance of north tropical Atlantic SST. Oceanic forcing from outside the region has been suspect, as has land snow-cover anomalies and the stratosphere. All are plausible influences that come with some support from relatively idealized model simulations. Taking this "extra" persistence into account results in about $10 \%-15 \%$ of the interannual variability that can possibly be predicted, not considering the effect of volcanism. While small, this assessment regarding marginal predictability might be useful to certain end users. The challenge in making forecasts of such variability is to demonstrate the reliability of such forecasts. Moreover, it should be noted that marginal S/I predictability may be linked with more predictable decadal variations, including trends due to external forcing, and not only to intraseasonal processes. Such predictability has a larger impact when longer time intervals are considered. In all, our community would be well advised to accept that the climate of the North Atlantic, and of Europe in particular, is dominated by a mode of climatic variability that is largely unpredictable. We can, perhaps, take comfort from the fact that recognizing the fundamental unpredictability of the atmosphere was arguably the greatest scientific achievement to emerge from our field in the past century (Lorenz 1963).

In the Tropics the prevailing notion is that potentially predictable signal is large because of thermodynamic coupling that enhances the persistence of SST anomalies, and the associated persistent changes in atmospheric circulation and rainfall. Because this potential stems from ocean-atmosphere coupling, research in this area should focus on developing better coupled models or new coupling strategies that can overcome the limitations of the two-tiered system.

Continued improvement of ENSO prediction is clearly important for advancing Atlantic sector prediction. Not enough is known about the interplay between local conditions and the remote forcing and how that depends on the intensity of the remote forcing and the season. In the particular case of the tropical Atlantic, the influence from the relatively unpredictable extratropical dynamics can be considered an external source of variability, interfering with the more predictable ENSO influence.

Acknowledgments. This paper was presented at the CLIVAR Workshop on Atlantic Predictability that took place at the University of Reading, Berkshire, United Kingdom, between 19 and 22 April 2004. Y. K. acknowledges support from NOAA Office of Global Programs under Grant NA16GP1574 and NSF under Grant ATM-0347009. W. R. acknowledges the support of NOAA's CLIVAR Atlantic program and of the NSF under Grant ATM-0237304. P. C. was supported by NOAA and NSF through Research Grants NA16GP1572, NA16GP2020, and ATM-0337846 and by NASA's Seasonal-to-Interannual Prediction Project through Interagency Agreement W-19, 750. P. C. also acknowledges the support from the National Natural Science Foundation of China (NSFC) through Grant 40128003. A. R. acknowledges support of NOAA Grant NA03OAR4320179. We thank Jennifer Velez for help with figures and analysis.

\section{REFERENCES}

Alexander, M. A., and C. Deser, 1995: A mechanism for the recurrence of wintertime midlatitude SST anomalies. J. Phys. Oceanogr., 25, 122-137.

— - - and M. S. Timlin, 1999: The reemergence of SST anomalies in the North Pacific Ocean. J. Climate, 12, 24192433.

Baldwin, M. P., and Coauthors, 2001: The quasi-biennial oscillation. Rev. Geophys., 39, 179-229.

- D. B. Stephenson, D. W. J. Thompson, T. J. Dunkerton, A. J. Charlton, and A. O'Neill, 2003a: Stratospheric memory and skill of extended-range weather forecasts. Science, 301, 636-640.

- D. W. J. Thompson, E. F. Shuckburgh, W. A. Norton, and N. P. Gillett, 2003b: Weather from the stratosphere? Science, 301, 317.

Barnston, A., and R. E. Livezey, 1987: Classification, seasonality and persistence of low-frequency circulation patterns. Mon. Wea. Rev., 115, 1083-1126.

Barreiro, M., P. Chang, and R. Saravanan, 2002: Variability of the South Atlantic convergence zone simulated by an atmospheric general circulation model. J. Climate, 15, 745-763.

- A. Giannini, P. Chang, and R. Saravanan, 2004: On the role of South Atlantic atmospheric circulation in tropical Atlantic variability. Earth's Climate: The Ocean-Atmosphere Interaction, Geophys. Monogr., Vol. 147, Amer. Geophys. Union, 143-152.

Barsugli, J. J., and D. S. Battisti, 1998: The basic effects of atmosphere-ocean thermal coupling on midlatitude variability. $J$. Atmos. Sci., 55, 477-493.

Bjerknes, J., 1964: Atlantic air-sea interaction. Advances in Geophysics, Vol. 10, Academic Press, 1-82.

_ 1966: A possible response of the atmospheric Hadley circulation to equatorial anomalies of ocean temperature. Tellus, 18, 821-828.

Bladé, I., 1997: The influence of midlatitude ocean-atmosphere coupling on the low-frequency variability of a GCM. Part I: No tropical SST forcing. J. Climate, 10, 2087-2106.

Bretherton, C. S., and D. S. Battisti, 2000: An interpretation of the results from atmospheric general circulation models forced by the time history of the observed sea surface temperature distribution. Geophys. Res. Lett., 27, 767-770.

Carton, J. A., and B. H. Huang, 1994: Warm events in the tropical Atlantic. J. Phys. Oceanogr., 24, 888-903.

Cassou, C., C. Deser, L. Terray, J. W. Hurrell, and M. Drévillon, 2004: Summer sea surface temperature conditions in the North Atlantic and their impact upon the atmospheric circulation in early winter. J. Climate, 17, 3349-3363.

Cazes-Boezio, G., A. W. Robertson, and C. R. Mechoso, 2003: 
Seasonal dependence of ENSO teleconnections over South America and relationships with precipitation in Uruguay. $J$. Climate, 16, 1159-1176.

Chang, P., R. Saravanan, L. Ji, and G. C. Hegerl, 2000: The effect of local sea surface temperatures on the atmospheric circulation over the tropical Atlantic sector. J. Climate, 13, 21952216.

__ L. Ji, and R. Saravanan, 2001: A hybrid coupled model study of tropical Atlantic variability. J. Climate, 14, 361-390.

__, R. Saravanan, and L. Ji, 2003: Tropical Atlantic seasonal predictability: The roles of El Nino remote influence and thermodynamic air-sea feedback. Geophys. Res. Lett., 30, 1501, doi:10.1029/2002GL016119.

Chen, P., and W. A. Robinson, 1992: Propagation of planetary waves between the troposphere and stratosphere. J. Atmos. Sci., 49, 2533-2545.

Chiang, J. C. H., and A. H. Sobel, 2002: Tropical tropospheric temperature variations caused by ENSO and their influence on the remote tropical climate. J. Climate, 15, 2616-2631.

—, Y. Kushnir, and A. Giannini, 2002: Deconstructing Atlantic ITCZ variability: Influence of the local cross-equatorial SST gradient, and remote forcing from the eastern equatorial $\mathrm{Pa}-$ cific. J. Geophys. Res., 107, 4004, doi:10.1029/2000JD000307.

Cohen, J., and D. Entekhabi, 1999: Eurasian snow cover variability and Northern Hemisphere climate predictability. Geophys. Res. Lett., 26, 345-348.

Czaja, A., and C. Frankignoul, 2002: Observed impact of Atlantic SST anomalies on the North Atlantic Oscillation. J. Climate, 15, 606-623.

__, P. van der Vaart, and J. Marshall, 2002: A diagnostic study of the role of remote forcing in tropical Atlantic variability. $J$. Climate, 15, 3280-3290.

Deser, C., and M. L. Blackmon, 1993: Surface climate variations over the North Atlantic Ocean during winter: 1900-1989. J. Climate, 6, 1743-1753.

DeWeaver, E., and S. Nigam, 2000: Zonal-eddy dynamics of the North Atlantic Oscillation. J. Climate, 13, 3893-3914.

Enfield, D. B., and D. A. Mayer, 1997: Tropical Atlantic sea surface temperature variability and its relation to El Nino Southern Oscillation. J. Geophys. Res., 102C, 929-945.

— A. M. Mestas-Nunez, D. A. Mayer, and L. Cid-Serrano, 1999: How ubiquitous is the dipole relationship in tropical Atlantic sea surface temperatures? J. Geophys. Res., 104C, 7841-7848

Feldstein, S. B., 2000a: The timescale, power spectra, and climate noise properties of teleconnection patterns. J. Climate, 13, $4430-4440$.

_ 2000b: Is interannual zonal mean flow variability simply climate noise? J. Climate, 13, 2356-2362.

Fontaine, B., and S. Bigot, 1993: West African rainfall deficits and sea-surface temperatures. Int. J. Climatol., 13, 271-285.

Franzke, C., S. Lee, and S. B. Feldstein, 2004: Is the North Atlantic Oscillation a breaking wave? J. Atmos. Sci., 61, 145160.

Giannini, A., R. Saravanan, and P. Chang, 2003: Oceanic forcing of Sahel rainfall on interannual to interdecadal time scales. Science, 302, 1027-1030.

- — $—$, and $—$ 2004: The preconditioning role of Tropical Atlantic variability in the development of the ENSO teleconnection: Implications for the prediction of Nordeste rainfall. Climate Dyn., 22, 839-855.

Goddard, L., and S. J. Mason, 2002: Sensitivity of seasonal climate forecasts to persisted SST anomalies. Climate Dyn., 19, 619631

Goldenberg, S. B., and L. J. Shapiro, 1996: Physical mechanisms for the association of El Nino and West African rainfall with Atlantic major hurricane activity. J. Climate, 9, 1169-1187.

Gong, G., D. Entekhabi, and J. Cohen, 2003: Relative impacts of Siberian and North American snow anomalies on the winter Arctic Oscillation. Geophys. Res. Lett., 30, 1209, doi:10.1029 2002 GL016135.

— — - and _ 2004: Orographic constraints on a modeled Siberian snow-tropospheric-stratospheric teleconnection pathway. J. Climate, 17, 1176-1189.

Haarsma, R. J., E. J. D. Campos, and F. Molteni, 2003: Atmospheric response to South Atlantic SST dipole. Geophys. Res. Lett., 30, 1864, doi:10.1029/2003GL017829.

Hastenrath, S., 1978: On modes of tropical circulation and climate anomalies. J. Atmos. Sci., 35, 2222-2231.

_ 1984: Interannual variability and annual cycle-Mechanisms of circulation and climate in the tropical Atlantic sector. Mon. Wea. Rev., 112, 1097-1107.

_ 2000: Upper air mechanisms of the Southern Oscillation in the tropical Atlantic sector. J. Geophys. Res., 105, $14997-$ 15009 .

_ 2002: Dipoles, temperature gradients, and tropical climate anomalies. Bull. Amer. Meteor. Soc., 83, 735-738.

— L. C. Castro, and P. Acietuno, 1987: The Southern Oscillation in the tropical Atlantic sector. Contrib. Atmos. Phys., 60, 447-463.

Haynes, P. H., M. E. McIntyre, T. G. Shepherd, C. J. Marks, and K. P. Shines, 1991: On the "downward control" of extratropical diabatic circulations by eddy-induced mean zonal forces. J. Atmos. Sci., 48, 651-680.

Hirst, A. C., and S. Hastenrath, 1983: Atmosphere ocean mechanisms of climate anomalies in the Angola tropical Atlantic sector. J. Phys. Oceanogr., 13, 1146-1157.

Hoerling, M. P., J. W. Hurrell, and T. Y. Xu, 2001: Tropical origins for recent North Atlantic climate change. Science, 292, 90-92.

,,,--- G. T. Bates, and A. S. Phillips, 2004: Twentieth century North Atlantic climate change. Part II: Understanding the effect of the Indian Ocean warming. Climate Dyn., 23, 391-405.

Holton, J. R., and H. C. Tan, 1980: The Influence of the equatorial quasi-biennial oscillation on the global circulation at $50 \mathrm{Mb}$. J. Atmos. Sci., 37, 2200-2208.

Hoskins, B. J., and D. J. Karoly, 1981: The steady linear response of a spherical atmosphere to thermal and orographic forcing. J. Atmos. Sci., 38, 1179-1196.

Houghton, R. W., and Y.M. Tourre, 1992: Characteristic lowfrequency sea surface temperature fluctuations in the tropical Atlantic. J. Climate, 5, 765-771.

Huang, B. H., and J. Shukla, 1997: Characteristics of the interannual and decadal variability in a general circulation model of the tropical Atlantic Ocean. J. Phys. Oceanogr., 27, 1693 1712.

- P. S. Schopf, and Z. Q. Pan, 2002: The ENSO effect on the tropical Atlantic variability: A regionally coupled model study. Geophys. Res. Lett., 29, 2039, doi:10.1029/ 2002GL014872.

Hurrell, J. W., 1995: Decadal trends in the North-Atlantic Oscillation-Regional temperatures and precipitation. Science, 269, 676-679.

, Y. Kushnir, G. Ottersen, and M. Visbeck, 2002: An over- 
view of the North Atlantic Oscillation. The North Atlantic Oscillation: Climatic Significance and Environmental Impact, Geophys. Monogr., Vol. 134, Amer. Geophys. Union, 1-35.

Kaplan, A., M. A. Cane, Y. Kushnir, A. C. Clement, M. B. Blumenthal, and B. Rajagopalan, 1998: Analyses of global sea surface temperature 1856-1991. J. Geophys. Res., 103, 18 567-18 589.

Klein, S. A., B. J. Soden, and N. C. Lau, 1999: Remote sea surface temperature variations during ENSO: Evidence for a tropical atmospheric bridge. J. Climate, 12, 917-932.

Kushner, P. J., and L. M. Polvani, 2004: Stratosphere-troposphere coupling in a relatively simple AGCM: The role of eddies. $J$. Climate, 17, 629-639.

Kushnir, Y., 1994: Interdecadal variations in North Atlantic sea surface temperature and associated atmospheric conditions. J. Climate, 7, 141-157.

- and J. M. Wallace, 1989: Low-frequency variability in the Northern Hemisphere winter-Geographical-distribution, structure and time-scale dependence. J. Atmos. Sci., 46, 31223142 .

- W. A. Robinson, I. Bladé, N. M. J. Hall, S. Peng, and R. T. Sutton, 2002a: Atmospheric GCM response to extratropical SST anomalies: Synthesis and evaluation. J. Climate, 15, 2233-2256.

— R. Reager, J. Miller, and J. C. H. Chiang, 2002b: A simple coupled model of tropical Atlantic decadal climate variability. Geophys. Res. Lett., 29, 2133, doi:10.1029/2002GL015874.

Latif, M., and T. P. Barnett, 1995: Interactions of the tropical oceans. J. Climate, 8, 952-964.

Lee, S., and H.-K. Kim, 2003: The dynamic relationship between subtropical and eddy-driven jets. J. Climate, 60, 1490-1503.

Leith, C. E., 1973: The standard error to time-average estimates of climatic means. J. Appl. Meteor., 12, 1066-1069.

Limpasuvan, V., and D. L. Hartmann, 2000: Wave-maintained annular modes of climate variability. J. Climate, 13, 4414-4429.

Lin, H., and J. Derome, 2003: The atmospheric response to North Atlantic SST anomalies in seasonal prediction experiments. Tellus, 55A, 193-207.

Lorenz, E. N., 1963: Deterministic nonperiodic flow. J. Atmos. Sci., 20, 130-148.

Madden, R. A., 1976: Estimates of the natural variability of timeaveraged sea-level pressure. Mon. Wea. Rev., 104, 942-952.

Mitchell, T. P., and J. M. Wallace, 1992: The annual cycle in equatorial convection and sea surface temperature. J. Climate, 5, $1140-1156$.

Mo, K. C., and S. Hakkinen, 2001: Interannual variability in the tropical Atlantic and linkages to the Pacific. J. Climate, 14, 2740-2762.

—_ and J. N. Paegle, 2001: The Pacific-South American modes and their downstream effects. Int. J. Climatol., 21, 1211-1229.

Moura, A. D., and J. Shukla, 1981: On the dynamics of droughts in northeast Brazil-observations, theory and numerical experiments with a general-circulation model. J. Atmos. Sci., 38, 2653-2675.

Murtugudde, R. G., J. Ballabrera-Poy, J. Beauchamp, and A. J. Busalacchi, 2001: Relationship between zonal and meridional modes in the tropical Atlantic. Geophys. Res. Lett., 28, 4463 4466.

Neelin, J. D., C. Chou, and H. Su, 2003: Tropical drought regions in global warming and El Nino teleconnections. Geophys. Res. Lett., 30, L24204, doi:10.1029/2004GL021072.

Nicholson, S. E., and D. Entekhabi, 1987: Rainfall variability in equatorial and southern Africa-Relationships with sea sur- face temperatures along the southwestern coast of Africa. $J$. Climate Appl. Meteor., 26, 561-578.

Nobre, P., and J. Shukla, 1996: Variations of sea surface temperature, wind stress, and rainfall over the tropical Atlantic and South America. J. Climate, 9, 2464-2479.

O'Sullivan, D., and M. L. Salby, 1990: Coupling of the quasibiennial oscillation and the extratropical circulation in the stratosphere through planetary wave transport. J. Atmos. Sci., 47, 650-673.

Peng, S. L., W. A. Robinson, and S. L. Li, 2002: North Atlantic SST forcing of the NAO and relationships with intrinsic hemispheric variability. Geophys. Res. Lett., 29, 1276, doi:10.1029/2001GL014043.

,,--- , and M. P. Hoerling, 2005: Mechanisms of the NAO response to the North Atlantic SST tripole. J. Climate, 18, 480-496.

Perlwitz, J., and N. Harnik, 2003: Observational evidence of a stratospheric influence on the troposphere by planetary wave reflection. J. Climate, 16, 3011-3026.

Robertson, A. W., and C. R. Mechoso, 2003: Circulation regimes and low-frequency oscillations in the South Pacific sector. Mon. Wea. Rev., 131, 1566-1576.

— - _ and Y. J. Kim, 2000: The influence of Atlantic sea surface temperature anomalies on the North Atlantic Oscillation. J. Climate, 13, 122-138.

Robock, A., 2000: Volcanic eruptions and climate. Rev. Geophys., 38, 191-219.

Rodwell, M. J., 2002: On the predictability of the North Atlantic Oscillation. The North Atlantic Oscillation: Climatic Significance and Environmental Impact, Geophys. Monogr., Vol. 134, Amer. Geophys. Union, 173-192.

_, and C. K. Folland, 2002: Atlantic air-sea interaction and seasonal predictability. Quart. J. Roy. Meteor. Soc., 128, 1413-1443.

- D. P. Powell, and C. K. Folland, 1999: Oceanic forcing of the wintertime North Atlantic Oscillation and European climate. Nature, 398, 320-323.

Rouault, M., S. A. White, C. J. C. Reason, J. R. E. Lutjeharms, and I. Jobard, 2002: Ocean-atmosphere interaction in the Agulhas Current region and a south African extreme weather event. Wea. Forecasting, 17, 655-669.

Ruiz-Barradas, A., J. A. Carton, and S. Nigam, 2000: Structure of interannual-to-decadal climate variability in the tropical Atlantic sector. J. Climate, 12, 1-43.

Saravanan, R., and P. Chang, 2000: Interactions between tropical Atlantic variability and El Nino-Southern Oscillation. J. Climate, 13, 2177-2194.

— and - 2004: Thermodynamic coupling and predictability of tropical sea surface temperature. Earth's Climate: The Ocean-Atmosphere Interaction, Geophys. Monogr., Vol. 147, Amer. Geophys. Union, 171-180.

Seager, R., Y. Kushnir, M. Visbeck, N. Naik, J. Miller, G. Krahmann, and H. Cullen, 2000: Causes of Atlantic Ocean climate variability between 1958 and 1998. J. Climate, 13, 2845-2862.

_ - , P. Chang, N. H. Naik, J. Miller, and W. Hazeleger, 2001: Looking for the role of the ocean in tropical Atlantic decadal climate variability. J. Climate, 14, 638-655.

_ , N. Harnik, Y. Kushnir, W. A. Robinson, and J. Miller, 2003: Mechanisms of hemispherically symmetric climate variability. J. Climate, 16, 2960-2978.

Servain, J., 1991: Simple climatic indices for the tropical Atlantic Ocean and some applications. J. Geophys. Res., 96, $15137-$ 15146. 
— I. Wainer, J. P. McCreary, and A. Dessier, 1999: Relationship between the equatorial and meridional modes of climatic variability in the tropical Atlantic. Geophys. Res. Lett., 26, 485-488.

- — - H. L. Ayina, and H. Roquet, 2000: The relationship between the simulated climatic variability modes of the tropical Atlantic. Int. J. Climatol., 20, 939-953.

Shapiro, L. J., and S. B. Goldenberg, 1998: Atlantic sea surface temperatures and tropical cyclone formation. J. Climate, 11, 578-590.

Song, Y., and W. A. Robinson, 2004: Dynamical mechanisms for stratospheric influences on the troposphere. J. Atmos. Sci., 61, 1711-1725.

Stenchikov, G., K. Hamilton, A. Robock, V. Ramaswamy, and M. D. Schwarzkopf, 2004: Arctic Oscillation response to the 1991 Pinatubo eruption in the SKYHI general circulation model with a realistic quasi-biennial oscillation. J. Geophys. Res., 109, D03112, doi:10.1029/2003JD003699.

Sterl, A., and W. Hazeleger, 2003: Coupled variability and air-sea interaction in the South Atlantic Ocean. Climate Dyn., 21, $559-571$.

Sutton, R. T., and D. L. R. Hodson, 2003: Influence of the oceans on North Atlantic climate variability 1871-1999. J. Climate, 16, 3296-3313.

— S. P. Jewson, and D. P. Rowell, 2000: The elements of climate variability in the tropical Atlantic region. J. Climate, 13, 3261-3284.

Tanaka, H. L., and H. Tokinaga, 2002: Baroclinic instability in high latitudes induced by polar vortex: A connection to the Arctic Oscillation. J. Atmos. Sci., 59, 69-82.

Thompson, D. W. J., and J. M. Wallace, 2000: Annular modes in the extratropical circulation. Part I: Month-to-month variability. J. Climate, 13, 1000-1016.

, and _ 2001: Regional climate impacts of the Northern Hemisphere annular mode. Science, 293, 85-89.
Trenberth, K. E., G. W. Branstator, D. Karoly, A. Kumar, N. C. Lau, and C. Ropelewski, 1998: Progress during TOGA in understanding and modeling global teleconnections associated with tropical sea surface temperatures. J. Geophys. Res., 103C, 14 291-14 324.

Venegas, S. A., L. A. Mysak, and D. N. Straub, 1997: Atmosphere-ocean coupled variability in the South Atlantic. $J$. Climate, 10, 2904-2920.

Visbeck, M., E. P. Chassignet, R. G. Curry, T. L. Delworth, R. R. Dickson, and G. Krahmann, 2002: The ocean's response to North Atlantic Oscillation variability. The North Atlantic Oscillation: Climatic Significance and Environmental Impact, Geophys. Monogr., Vol. 134, Amer. Geophys. Union, 113145.

Walker, G. T., 1924: Correlations in seasonal variations of weather IX. Mem. Ind. Meteor. Dept., 24, 687-692.

_ and E. W. Bliss, 1932: World Weather V. Mem. Roy. Meteor. Soc., 4, 53-84.

Wallace, J. M., 2000: North Atlantic Oscillation/Annular Mode: Two paradigms-one phenomenon. Quart. J. Roy. Meteor. Soc., 126, 791-805.

_, and D. S. Gutzler, 1981: Teleconnections in the geopotential height field during the Northern Hemisphere winter. Mon. Wea. Rev., 109, 784-812.

_ C. Smith, and C. S. Bretherton, 1992: Singular value decomposition of wintertime sea surface temperature and $500-\mathrm{mb}$ height anomalies. J. Climate, 5, 561-576.

Xie, S.-P., 1999: A dynamic ocean-atmosphere model of the tropical Atlantic decadal variability. J. Climate, 12, 64-70.

— terns, mechanisms, and impacts. Ocean-Atmosphere Interaction and Climate Variability, Geophys. Monogr., Vol. 147, Amer. Geophys. Union, 121-142.

Zebiak, S. E., 1993: Air-sea interaction in the equatorial Atlantic region. J. Climate, 6, 1567-1568. 